\title{
Systematic Errors in South Asian Monsoon Precipitation: Process-Based Diagnostics and Sensitivity to Entrainment in NCAR Models
}

\author{
FRANZISKA S. HANF \\ International Pacific Research Center, University of Hawai'i at Mānoa, Honolulu, Hawaii \\ H. ANNAMALAI \\ International Pacific Research Center, and Department of Oceanography, University of Hawai ‘i at Mānoa, Honolulu, Hawaii
}

(Manuscript received 1 August 2018, in final form 19 November 2019)

\begin{abstract}
In simulations of the boreal summer Asian monsoon, generations of climate models show a persistent climatological wet bias over the tropical western Indian Ocean and a dry bias over South Asia. Here, focusing on the monsoon developing stages (May-June), process-based diagnostics are first applied to a suite of NCAR models and reanalysis products. Two primary factors are identified for the initiation and maintenance of the wet bias over the northwestern Indian Ocean (NWIO; $5^{\circ}-15^{\circ} \mathrm{N}, 52^{\circ}-67^{\circ} \mathrm{E}$ ): (i) excessive tropospheric moisture and (ii) restrained horizontal advection of the 1000-800-hPa levels cold-dry air couplet that originates offshore of Somalia. Second, guided by the diagnostics, we hypothesized that insufficient dilution of convective updrafts is one possible candidate for model bias and performed a series of enhanced entrainment sensitivity experiments with NCAR CAM4. Over the NWIO, the results suggest that globally increasing the maximum entrainment rate $\varepsilon_{\max }$ leads to a drier free troposphere, arrests the vertical extension of clouds, and weakens moisture-convection and cloud-radiation feedbacks; each factor contributes to a reduced wet bias. Moreover, a higher $\varepsilon_{\max }$ leads to a reduced dry bias over South Asia through changes in the local circulation features. In CAM4, improved precipitation climatology due to increased $\varepsilon_{\max }$ suggests that insufficient dilution is one factor, but not the only one, that contributes to systematic errors. Rather, realistic representation of boundary layer processes in climate models arising out of local ocean-atmosphere interaction processes off Somalia's coast deserves attention in reducing the NWIO wet bias.
\end{abstract}

\section{Introduction}

\section{a. Background}

In the tropics, understanding and modeling the response of small-scale convection to large-scale forcing is a grand challenge (e.g., Bretherton et al. 2006; Raymond et al. 2009). This difficulty is compounded by the fact that small-scale diabatic processes exert considerable impact on the large-scale features. The ability of numerical general circulation models (GCMs) to accurately simulate these tropical features is crucially dependent on the performance of their convection and cloud parameterization schemes and their interactions. However, despite decades of sustained research and demonstrated improvements (e.g., Neale et al. 2008; Zhao et al. 2018a,b),

Corresponding author: Franziska S. Hanf, franziska.hanf@unihamburg.de realistic simulation of precipitation-generating processes is still an ongoing challenge for GCMs. Therefore, identifying sources of model errors is a necessary first step to achieve progress in tropical rainfall simulation.

A prominent systematic error that almost all state-ofthe-art GCMs depict in their mean summer monsoon basic state, as evidenced by phase 5 of the Coupled Model Intercomparison Project (CMIP5) multimodel mean in Sperber et al. (2013), is a wet bias over a large region in the tropical western Indian Ocean, while a dry bias exists over South Asia (Fig. 1). This structure of the model error is consistent between the two recent generations of CMIP models, even though its amplitude is smaller in CMIP5 relative to CMIP3 (Sperber et al. 2013). Its persistence between different model families, even between members of the same model family over decades (e.g., Zhao et al. 2018a,b), indicates the degree of complexity in representing the interactive processes that shape the monsoon convection. Recently, Annamalai et al. (2017) 
mean JJAS precipitation bias

(a) CCSM4 minus TRMM

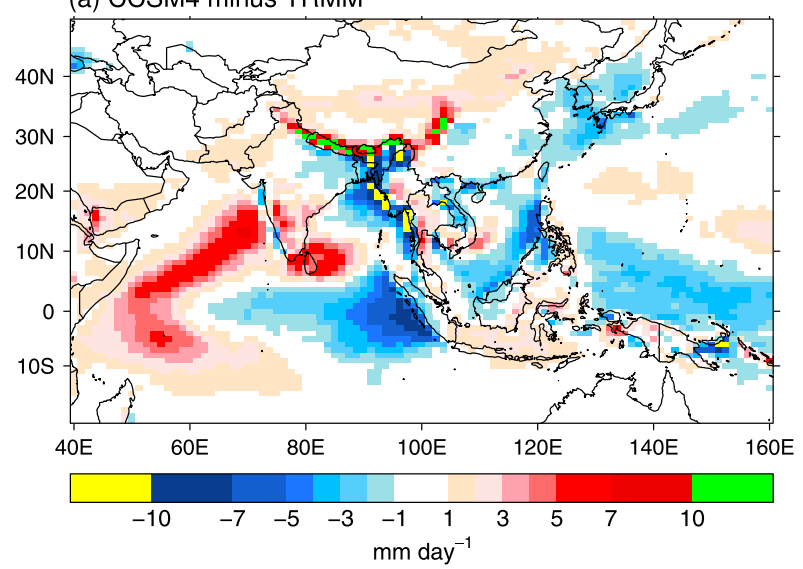

(b) CCSM4 minus GPCP

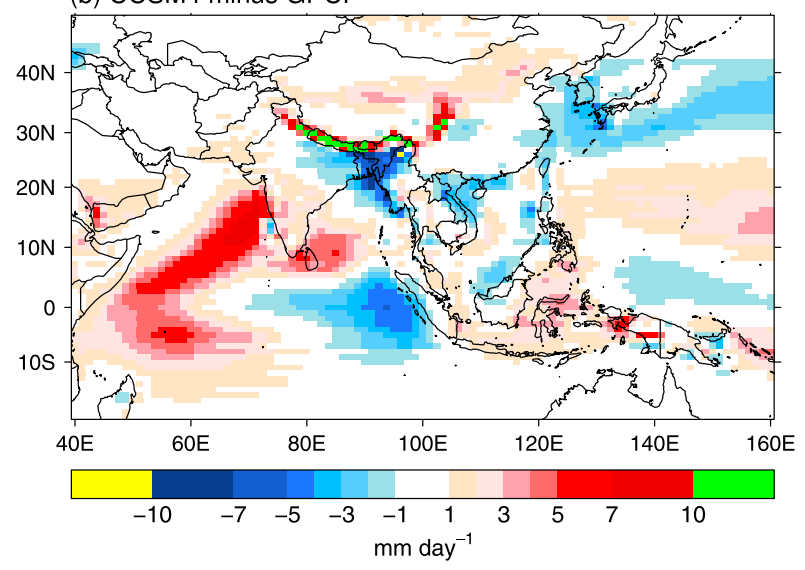

FIG. 1. June-September averaged precipitation climatology bias $\left(\mathrm{mm} \mathrm{day}{ }^{-1}\right.$ ) from (a) CCSM4 with respect to TRMM (1998-2014) and (b) CCSM4 with respect to GPCP (1979-2005).

showed that it is during the monsoon developing stages from May to June that the CMIP5 model errors begin to emerge in the western equatorial Indian Ocean (WEIO). Earlier, Martin et al. (2010) and Ma et al. (2014) performed initialized hindcast experiments and also noted that model errors in precipitation first emerge over the western Indian Ocean. A pertinent question is, in the climatologically dry regions of the western Indian Ocean, why do climate models simulate a wet bias?

Observed monthly precipitation climatology shows that the WEIO receives a local maximum $\left(\sim 4 \mathrm{~mm}_{\text {day }}{ }^{-1}\right)$ during May when sea surface temperature (SST) also peaks there (Annamalai et al. 2017). During most other months, the observed precipitation is less than $3 \mathrm{~mm}_{\text {day }}{ }^{-1}$ and SSTs are lower, except during November-January. In contrast, the eastern equatorial Indian Ocean receives high rainfall $\left(>6 \mathrm{~mm} \mathrm{day}^{-1}\right)$ throughout the annual cycle with a peak around $10-12 \mathrm{~mm} \mathrm{day}^{-1}$ during October-December.
In response to the east-west contrast in precipitation and associated diabatic heating, an east-west overturning circulation prevails along the equatorial Indian Ocean with implied subsidence in the west (e.g., Webster et al. 1998). Once the southwest monsoon develops and intensifies during May and June, southerly winds upwell cold subsurface waters off the Somalia-Oman coasts. Subsequent advection by oceanic processes reduces SST to less than $26^{\circ} \mathrm{C}$ over the central Arabian Sea (McCreary et al. 1993; Shenoi et al. 2002). Furthermore, atmospheric Rossby wave descent, forced by Bay of Bengal convection (Rodwell and Hoskins 1996), limits deep convection and precipitation in the Arabian Sea. In summary, local air-sea interactions and remotely forced atmospheric subsidence are known to be important factors for the observed climatologically dry regions of the western Indian Ocean. While some of the factors are consequences of the monsoon itself, it is challenging to identify and isolate model processes that initiate the wet bias over the western Indian Ocean. We intend to do so here.

Recent studies have addressed the question of identifying source(s) of model errors in the simulation of dry biases over South Asia and wet biases over the western Indian Ocean. Potential error sources include representation of orography in regions of sharp low-level moist static energy (MSE) gradients (Boos and Hurley 2013), fast atmospheric processes (Martin et al. 2010; Ma et al. 2014), and too-strong Bjerknes' feedback in the equatorial Indian Ocean (Annamalai et al. 2017). Both observations and cloud-resolving model studies note that transition from shallow to deep convection and hence precipitation intensity, particularly over the open oceans, is determined by free-tropospheric moisture (Tompkins 2001; Derbyshire et al. 2004; Bretherton et al. 2004; Holloway and Neelin 2009; Tulich and Mapes 2010). Recognizing that errors due to fast atmospheric processes may arise from convective processes, sensitivity of convection schemes to environmental humidity, particularly to increasing mixing entrainment and detrainment for deep and/or midlevel convection, have been tested in different GCMs that have employed different convection schemes and different ways to implement the fractional entrainment rates with height (e.g., Hirons et al. 2013a,b; Klingaman and Woolnough 2014b; Hannah and Maloney 2014; Bush et al. 2015; Zhao et al. 2018b). Briefly, revisions to the convection parameterization in terms of entrainment $\varepsilon$ and detrainment $\delta$ coefficients have notable imprints on cloud properties and precipitation partitioning leading to suppression of precipitation in drier environments (e.g., Bechtold et al. 2008; Hirons et al. 2013a,b; Lin and Zhao 2013; Zhao et al. 2018a,b; Klingaman and Woolnough 2014a,b). 
In the Global Atmosphere 3.0 (GA3.0) configuration of the Hadley Centre Global Environment Model, version 3 (HadGEM3), Bush et al. (2015) noted that increasing entrainment and detrainment rates reduces the WEIO wet bias but exacerbates the wet bias over the northwestern Pacific. Their results indicate that the response to increased entrainment and detrainment depends strongly on the regional mean state in which the convection occurs. Similar precipitation responses were observed in the Geophysical Fluid Dynamics Laboratory Atmospheric Model (GFDL AM4.0) by Zhao et al. (2018b), such as the amplification of the wet bias around the Philippines with increasing entrainment rates. For increased entrainment rates in the atmospheric part of the Model for Interdisciplinary Research on Climate, version 5 (MIROC5), Hirota et al. (2014) reported a reduction in the tropical Pacific double intertropical convergence zone bias.

Assessing the impact of enhanced entrainment on the Madden-Julian oscillation (MJO), a few modeling studies with (e.g., Klingaman and Woolnough 2014a) and without (Hirons et al. 2013a,b; Hannah and Maloney 2014; Klingaman and Woolnough 2014b) air-sea interactions noted an improved representation of MJO characteristics (spatial coherence and propagation) by suppressing light rain rates and allowing build up of moisture anomalies for a longer period of time during the MJO suppressed phase. While the time-mean state improves over the tropical Indian Ocean (e.g., Klingaman and Woolnough 2014b), it worsens elsewhere.

In summary, the sensitivity to entrainment in different modeling studies shows certain encouraging results, but the modeled monsoon precipitation errors worsen in other regions of the broader Asian summer monsoon. Questions remain, such as whether this feature of sensitivity to entrainment is model dependent in other regions; and, does it imply that model errors are due to multiple processes and their interactions? Therefore, it is often very difficult to retrace errors to particular subgrid-scale parameterization settings, and it suggests that model errors are may be due to fundamental problems with the assumptions made in their physical parameterizations.

\section{b. Present study}

With a goal of improving monsoon modeling, the present study seeks to continue the efforts in identifying and isolating the source of model errors in the simulation of monsoon precipitation climatology. To address this, we adopt a threefold approach: First, we perform a detailed time series analysis of dynamical and thermodynamical variables, focusing on the northwestern Indian Ocean (Arabian Sea) during the monsoon developing stages (May-June). The diagnostics are measured in the National Center for Atmospheric Research (NCAR) Community
Earth System Model (CESM) against observed precipitation and reanalyzed variables. Here, we assess the systematic errors in the vertical distribution of moisture and vertical motion fields. Second, we apply the vertically integrated MSE budget to identify the systematic biases in adiabatic and diabatic terms that act as sources and sinks of column moisture. Application of these process-based diagnostics is justified by the fact that in the deep tropics, where horizontal temperature gradients are small (e.g., Neelin and Held 1987), the surface precipitation rate is directly proportional to MSE convergence. Basic diagnostics (section 3) lead us to hypothesize that in the NCAR models a wet bias is associated with excessive moisture in the free troposphere and persisting deep convection. Several studies have indicated that such a model behavior can be linked to insufficient dilution of convective updrafts (i.e., low entrainment rates) in the standard NCAR model configurations (e.g., Wang and Zhang 2013; Hannah and Maloney 2014; Chen and Mapes 2018). More details on model entrainment-detrainment processes are discussed in section 2. From lessons learned from earlier modeling sensitivity studies with NCAR's Community Atmospheric Model (CAM) (Hannah and Maloney 2014; Chen and Mapes 2018) that low-entrainment plumes in convection schemes are associated with excessive deep convection triggering and overly high convective rainfall, we hypothesize that increasing the entrainment rate will reduce the climatological wet bias over the Arabian Sea in CAM. Third, to test the hypothesis, we perform a series of sensitivity experiments by enhancing the entrainment values systematically in the convection scheme of NCAR's Community Atmospheric Model, version 4 (CAM4), configuration. For all of the simulations, we apply process-based diagnostics to assess the direct and indirect effects of entrainment values on modeled precipitation.

The reminder of the manuscript is structured as follows. Section 2 provides a description of the CESM model family, the data used, and details about the budget diagnostics performed. In section 3 , the spatial and temporal evolution of the fourth version of the Community Climate System Model (CCSM4) bias over the northwestern Indian Ocean are reported, and possible causes of errors are discussed. In section 4 , the design of sensitivity experiments is outlined, followed by an evaluation of the results obtained from moisture and MSE budgets. Finally, a summary of the results and a discussion of the implications for the monsoon modeling are given in section 5 .

\section{Model, data, and method}

\section{a. CESM model family}

The model simulations diagnosed as well as the model employed to test the sensitivity of entrainment values 
are from the NCAR CESM model family. CESM is a fully coupled global climate model consisting of atmosphere, ocean, land, land ice, and sea ice components with the most recent model version, the CESM1-CAM5. The previous model is CCSM4 (Gent et al. 2011). While the CESM1-CAM5 comprises the same land, ocean, and sea ice components as CCSM4, an updated atmospheric model is included. Compared to CAM4 (Neale et al. 2010), CAM5 (Neale et al. 2012) contains a range of improvements in the representation of moist physical processes: for example, new moist planetary boundary layer (PBL) scheme, new shallow convection mass flux scheme, new two-moment bulk stratiform cloud microphysics, and revised cloud macrophysics. More details on the changes of parameterization components between CAM4 and CAM5 are documented in Neale et al. (2010, 2012).

CAM4 and CAM5 share the same deep convection parameterization that is based on the Zhang and McFarlane (1995) scheme. Briefly, this scheme uses an entraining plume ensemble approach that assumes the existence of an ensemble of convective updrafts (and associated saturated downdrafts) whenever the atmosphere is conditionally unstable in the lower troposphere. All condensation is assumed to take place within the updraft plumes that have a common value for their initial cloud-base upward mass flux. Rainwater is removed immediately from the updrafts by surface precipitation or evaporation. In the standard CAM4 and CAM5, a tuneable minimum threshold of convective available potential energy (CAPE) $=70 \mathrm{~J} \mathrm{~kg}^{-1}$ is required to initiate deep convection. Once deep convection is induced, the closure condition assumes that cumulus convection acts to remove CAPE exponentially according to a specified adjustment time scale of $\tau=$ $7200 \mathrm{~s}$ (=2 h) (Neale et al. 2010), meaning that the cloudbase mass flux $M_{\text {base }}$ is proportional to the amount of CAPE in the atmosphere. Of particular relevance to the focus here, the deep convection scheme uses entrainment in two ways: (i) to determine the reference buoyancy parcel profile to calculate the CAPE, which is used as a triggering criteria and for the strength of convection at cloud base; and (ii) in the cloud model itself to calculate the cloud entrainment-detrainment profile. To increase the model's sensitivity to environmental humidity, Neale et al. (2008) modified the original Zhang-McFarlane deep convection scheme by including a dilution approximation (mixing with environmental air) for the CAPE computation. These changes used in CAM4 and CAM5 relate to the closure part only and involve a tuneable globally prescribed constant entrainment rate $\left(\varepsilon_{\max }=\right.$ $1.0 \mathrm{~km}^{-1}$ ), which implies a doubling of air mass every $1.0 \mathrm{~km}$. In general, the plume calculation entrainment controls the calculation of CAPE used in the closure and sets the most undilute parcel properties, which is then used in the cloud model. There is no detrainment considered here.

In contrast, the cloud model entrainment-detrainment profile varies in space and time depending on the temperature and humidity profiles. The cloud model represents the updraft ensemble as a spectrum of clouds with individual fractional entrainment rates $\varepsilon(z)$ at height $z$ for each plume. The shallowest "plume" (highest allowed strength of detrainment) of the spectra is constructed to become neutrally buoyant at a minimum in saturated MSE. Above this minimum in environmental MSE, entraining parcels then successively detrain at higher levels with lower implied entrainment. The least-entraining "plume" follows that of the most undilute profile taken from the reference parcel calculation in item (i) above.

For each level, $\varepsilon(z)$ is evaluated numerically, and in typical cases it has a maximum in the lower troposphere and decreases with height above the top of the shallowest of the convective plumes $z_{0}$. Adding up all the plumes, the total entrainment rate $E_{u}$ will give a vertical profile of "bulk" or effective entrainment and can be written as

$$
E_{u}=\frac{M_{\text {base }}}{\varepsilon_{\max }} \int_{0}^{\varepsilon(z)} \varepsilon e^{\varepsilon\left(z-z_{\text {base }}\right)} d \varepsilon=\frac{\partial M_{u}}{\partial z}-D_{u},
$$

where $M_{u}$ is the ensemble cloud updraft mass flux, $z_{\text {base }}$ is the height of the cloud base, and $D_{u}$ is the total detrainment. Detrainment is confined to regions where $\varepsilon(z)$ decreases with height so that the total detrainment $D_{u}$ is zero below $z_{0}$ and

$$
D_{u}(z)=-\frac{M_{\text {base }}}{\varepsilon_{\max }} \frac{\partial \varepsilon(z)}{\partial z} \exp \left[\varepsilon(z)\left(z-z_{\text {base }}\right)\right]
$$

above $z_{0}$. It is assumed that the detrained air from the updrafts is saturated and evaporates locally into the environment (Zhang and McFarlane 1995).

\section{b. Data}

For an investigation of the systematic biases over the western Indian Ocean, NCAR model simulations diagnosed are taken from the CMIP5 data portal (Taylor et al. 2012). They include historical simulations from CCSM4 and CESM1-CAM5, and an AMIP-type integration of CCSM4 (herein referred to as CCSM4 AMIP) where the atmospheric component (CAM4) employed in CCSM4 is forced with observed SSTs. The model resolution of CAM4 and CAM5 is $1.25^{\circ} \times 0.9^{\circ}$ with 26 (30) vertical layers for CAM4 (CAM5).

To validate the model simulations, as a measure of the observed rainfall, we use the merged satellite 
precipitation product from the Tropical Rainfall Measuring Mission (TRMM) combined "TRMM and Other Satellite Precipitation Product" (3B42 V7) (Huffman et al. 2007, 2010) with $0.25^{\circ} \times 0.25^{\circ}$ horizontal resolution for the period 1998-2014. To test how sensitive the mean monsoon precipitation basic state model biases are to the choice of observational data, we also compared the model simulations with the merged precipitation product from the Global Precipitation Climatology Project (GPCP), version 2.2 (Adler et al. 2003; Huffman et al. 2009), with $2.5^{\circ} \times 2.5^{\circ}$ horizontal resolution for the period 1979-2005. The bulk of atmospheric data used throughout the study are taken from the ERA-Interim reanalysis (Dee et al. 2011) produced from the European Centre for Medium-Range Weather Forecasts (ECMWF). The ERA-Interim dataset has a $1^{\circ} \times 1^{\circ}$ horizontal resolution and 32 vertical pressure levels with 7 vertical levels from 1000 to $850 \mathrm{hPa}$.

We prepared monthly and daily climatologies for the model (1979-2005), observational (1998-2014), and reanalysis (1979-2005) data. For calculating model biases, we regridded the observed and reanalysis fields onto a common grid, using the coarsest resolution among the datasets compared (model grid; $1.25^{\circ} \times 0.9^{\circ}$ horizontal resolution)

\section{c. Moist static energy budget}

The interaction of the large-scale tropical circulation with deep moist convection requires the consideration of moisture and temperature (Back and Bretherton 2006) as phrased in the quantity of the moist static energy (MSE; $\mathrm{m}$ ):

$$
m=c_{p} T+g z+L q
$$

where $c_{p}$ is the specific heat capacity at constant pressure and $T$ is the temperature. Also, $g$ is the acceleration due to gravity, $z$ is the geopotential height, $L$ is the latent heat of condensation, and $q$ is the specific humidity. Equation (3) shows that MSE variations (specifically, temporal MSE variations) at constant temperature are almost equivalent to variations of specific humidity (Raymond et al. 2015). Thus the MSE budget becomes a useful approach for examining precipitation anomalies in the deep tropics (e.g., Hannah and Maloney 2014; Annamalai et al. 2017). Vertically integrated, the MSE budget is approximately given by

$$
\left\langle\frac{\partial m}{\partial t}\right\rangle=-\left\langle\omega \frac{\partial m}{\partial p}\right\rangle-\langle\mathbf{V} \cdot \nabla m\rangle+E+H+\mathrm{LW}+\mathrm{SW}
$$

where $\omega$ is the vertical pressure velocity, $p$ is the air pressure, $\mathbf{V}$ is the horizontal velocity vector, and $\nabla$ is the gradient operator. Also, $E$ and $H$ are the latent heat flux (evaporation) and the sensible heat flux at the surface, respectively. LW and SW are the net (top of the atmosphere minus surface) longwave and shortwave heating rates, respectively, and their sum accounts for the net radiative flux into the column $F_{\text {rad. }}$. The angle brackets \langle\rangle denote vertical integration through the atmospheric column. All terms are expressed in watts per square meter $\left(\mathrm{W} \mathrm{m}^{-2}\right)$. In Eq. (4), $\langle\partial m / \partial t\rangle$ represents the change in the storage term and describes the tendency for column moistening. All terms on the right-hand side of Eq. (4) are source and sink terms of column MSE, which are expressed through both adiabatic $(-\langle\omega \partial m / \partial p\rangle,-\langle\mathbf{V} \cdot \nabla m\rangle)$ and diabatic $(E, H, \mathrm{LW}, \mathrm{SW})$ terms. The adiabatic terms $-\langle\omega \partial m / \partial p\rangle$ and $-\langle\mathbf{V} \cdot \nabla m\rangle$ are the vertical and horizontal advection of MSE, respectively, and the latter can be split into horizontal advection of moisture $-\langle\mathbf{V} \cdot \nabla q\rangle$ and temperature $-\langle\mathbf{V} \cdot \nabla T\rangle$. For reasons discussed later in section $3 \mathrm{~b}$, we assume steady state, that is, $\langle\partial m / \partial t\rangle \approx 0$. Applying that on Eq. (4) leads to

$$
\left\langle\omega \frac{\partial m}{\partial p}\right\rangle=-\langle\mathbf{V} \cdot \nabla q\rangle-\langle\mathbf{V} \cdot \nabla T\rangle+E+H+F_{\text {rad }} .
$$

We are aware that adiabatic and diabatic MSE terms influence each other, and thus identifying the initial source of model error in a steady-state budget estimation approach has its own limitations. As MSE is approximately conserved (under hydrostatic approximation) in adiabatic moisture processes even if they undergo phase changes between vapor and liquid (Back and Bretherton 2006; Raymond et al. 2009), MSE gives a "stable measure" of the amount of precipitable water in atmospheric convection. The column-integrated vertical MSE advection $\langle\omega \partial m / \partial p\rangle$ represents the export/import of MSE by large-scale vertical motions and, as shown by Back and Bretherton (2006) and Bui et al. (2016), $\langle\omega \partial m / \partial p\rangle$ tends to be positive (negative) in the top-heavy (bottom heavy) structure of vertical motion implying export (import) of column MSE. For more details on the MSE framework the readers are referred to $\mathrm{Su}$ and Neelin (2002).

\section{Diagnosis of systematic errors over the northwestern Indian Ocean}

In this section, we begin with a brief description of the modeled mean monsoon precipitation followed by a detailed analysis of vertical profiles of moisture and vertical pressure velocity with a focus on monsoon developing stages (section $3 \mathrm{a}$ ). Then, we discuss results based on vertically integrated MSE budgets and the model biases in cross sections of MSE adiabatic terms are presented (section 3b). From these diagnostics, we formulate our working hypothesis. 


\section{a. Precipitation, specific humidity, and vertical pressure velocity}

\section{1) MeAn monsoon PRecipitation basic State}

Figure 1a shows the mean boreal summer (JuneSeptember) precipitation climatology bias from CCSM4 with respect to TRMM satellite-based observational estimates. In terms of spatial structure, the model errors correspond well with the systematic errors found in CMIP3/5 models (Sperber et al. 2013). Compared to TRMM, CCSM4 simulates a lack of rainfall along the monsoon trough (a low pressure region extending from central and northeastern India over the northern Bay of Bengal into the South China Sea) and along the centraleastern equatorial Indian Ocean. Excess precipitation is produced from $10^{\circ} \mathrm{S}$ to $20^{\circ} \mathrm{N}$ over the western Indian Ocean, off India's southeastern coast, over much of the southern part of India and along the Himalayan orography north of $25^{\circ} \mathrm{N}$. These model biases remain similar in CESM1-CAM5 too (not shown). A comparison with the GPCP merged precipitation product (Fig. 1b) reveals that the model biases are robust, and the main results of this study are not sensitive to the choice of observational data.

\section{2) "TIME WINDOW" MAY-JUNE}

Figures $2 \mathrm{a}$ and $2 \mathrm{~b}$ compare the mean May and June CCSM4 precipitation bias (CCSM4 minus TRMM) over the South Asian monsoon region, respectively. Superimposed are the monthly means of $850-\mathrm{hPa}$ horizontal wind climatology from CCSM4. In the Southern Hemisphere western Indian Ocean, along $10^{\circ} \mathrm{S}$, a wet bias is prominent during both May and June collocated with strong southeasterly trade winds. However, over the Northern Hemisphere western Indian Ocean, it is during the "time window" of the monsoon developing stages in May-June when the southwesterly low-level flow becomes established that the positive precipitation biases begin to emerge. More specifically, north of the equator, a dry bias that exists in May is replaced by a wet bias in June with a local maximum over the region $5^{\circ}-$ $15^{\circ} \mathrm{N}, 52^{\circ}-67^{\circ} \mathrm{E}$ (boxed region in Fig. 2b). Past studies have also noted that mean forecast errors of precipitation saturate after a few days of hindcasts in the vicinity of the region identified here with amplitudes comparable to long-term climate simulations (e.g., Martin et al. 2010; Ma et al. 2014), prompting a closer look at this region. Most of the diagnostics reported here and in the following sections are area averaged over this box (referred to herein as the "Arabian Sea").

Figure $2 \mathrm{c}$ shows the temporal evolution of 3-day running means of daily climatological precipitation averaged over the Arabian Sea from TRMM observations (dark blue), ERA-Interim (light blue), and from model simulations. The gray horizontal line marks a rainfall rate of $4 \mathrm{~mm}$ day $^{-1}$. TRMM observations reveal a "sudden burst" of rainfall (rapid rainfall increase) during early May with an approximate rate of increase of $0.47 \mathrm{~mm} \mathrm{day}^{-2}$. But the rainy season is only short-lived and high rainfall rates occur only until early June. We interpret the "sudden burst" of rainfall in mid-May as a manifestation of the surge of moisture-laden low-level winds in conjunction with high local evaporation due to both high wind speed and higher SST.

Compared to TRMM observations, rainfall evolution from ERA-Interim (light blue) shows a good agreement temporally but not in the intensity (e.g., TRMM shows higher rainfall during the rainy season in May-June, while ERA-Interim shows higher rainfall during the rest of the monsoon season). A direct comparison of rainfall intensity is masked by the fact that in data-sparse areas, such as the tropical Indian Ocean, the quality of precipitation estimates from the reanalysis is less constrained by in situ measurements of temperature and humidity and will depend more on the first guess produced by the forecast model (Dee et al. 2011) that is sensitive to the physical parameterizations used in the reanalysis model (Annamalai et al. 1999).

In Fig. 2c, the temporal evolution of modeled rainfall and SST for CESM1-CAM5 (green), CCSM4 (dark brown), and CCSM4 AMIP (orange) are also shown. In May, the coupled models CCSM4 and CESM1-CAM5 depict a dry bias that reverses sign in June, and the wet bias remains until mid-September. Numerous past studies (e.g., Levine et al. 2013; Marathayil et al. 2013; Annamalai et al. 2017) have shown that a cold SST bias over the northern Indian Ocean during boreal spring (March-May) in conjunction with weak SST warming in the southern Indian Ocean delay the poleward migration of the intertropical convergence zone (ITCZ). In fact, both coupled models show a climatological cold SST bias over the Arabian Sea during the premonsoon month of May with respect to ERA-Interim (Fig. 2c), likely explaining their delayed onset of "heavy rainfall" (dry bias from May to mid-June, Fig. 2c). The delay is more pronounced in CCSM4, and this phase shift is clear in that CCSM4 (CESM1-CAM5) simulates high rainfall $>4 \mathrm{~mm} \mathrm{day}^{-1}$ during July-August (June-July). We speculate that this improvement in CESM1-CAM5 may be related to a revised representation of moist physical processes from CAM4 to CAM5 (section 2a). Note that the "sudden burst" of heavy precipitation in early May is better captured using prescribed observed SSTs (CCSM4 AMIP). But in fact, a comparison between the coupled and uncoupled integrations shows that the wet bias during the observed climatological dry 


\section{precipitation bias (CCSM4 minus TRMM) / CCSM4 850hPa wind}

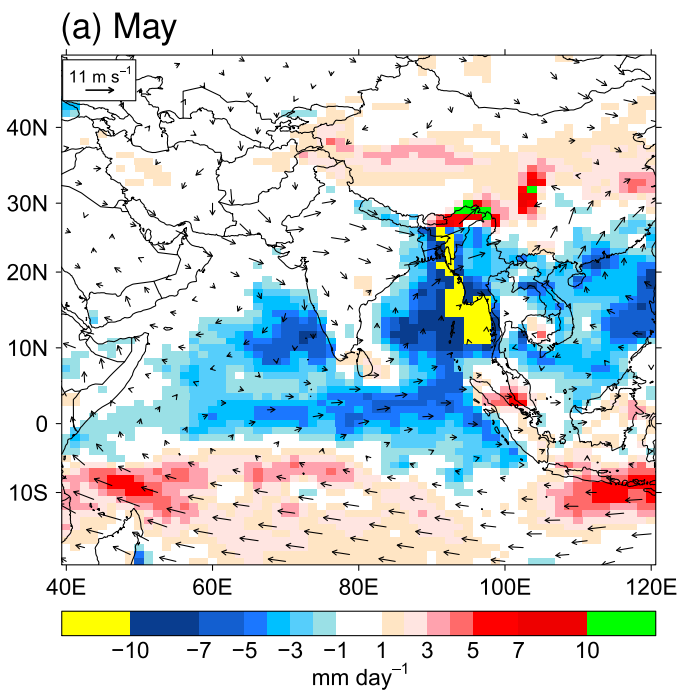

(b) June

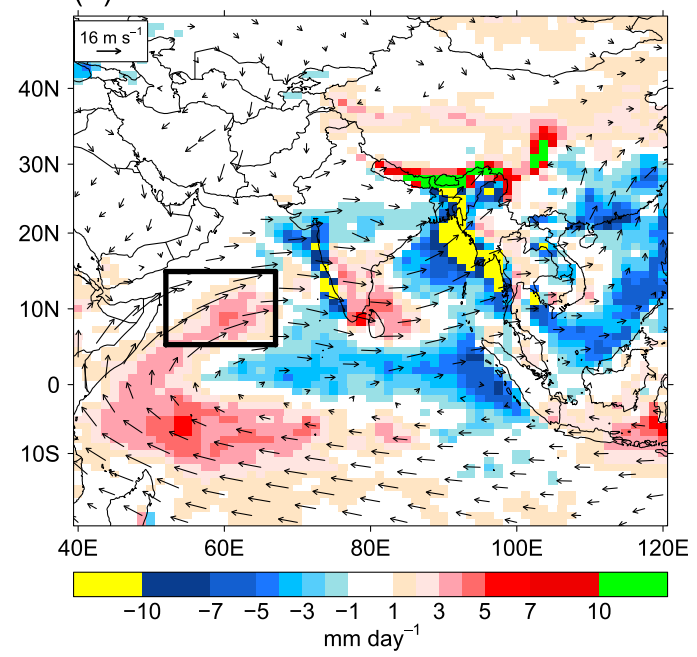

(c) daily precipitation climatology over Arabian Sea

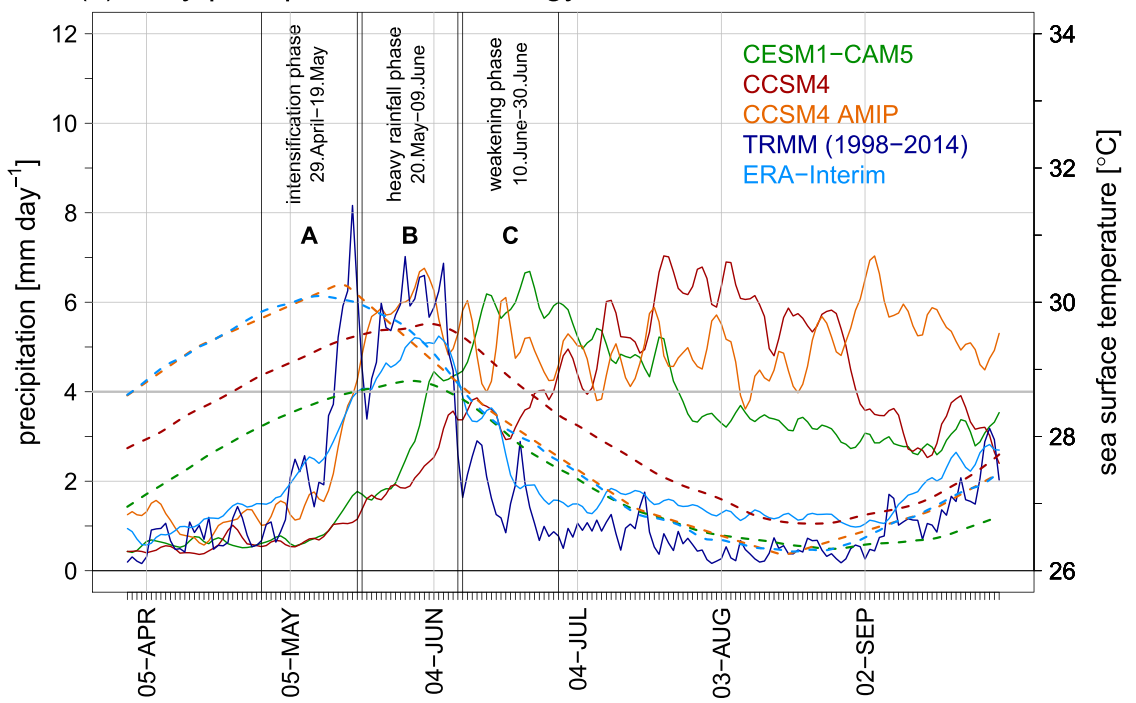

FIG. 2. Monthly mean precipitation climatology bias $\left(\mathrm{mm} \mathrm{day}^{-1}\right)$ from CCSM4 with respect to TRMM (shading) and monthly mean horizontal wind climatology $\left(\mathrm{m} \mathrm{s}^{-1}\right.$ ) at $850 \mathrm{hPa}$ from CCSM4 (arrows) for (a) May and (b) June. The black box in (b) indicates the Arabian Sea region $\left(5^{\circ}-15^{\circ} \mathrm{N}, 52^{\circ}-67^{\circ} \mathrm{E}\right)$. (c) The 3-day running means of Arabian Sea daily precipitation climatology ( $\mathrm{mm} \mathrm{day}^{-1}$; solid curves) and SST climatology $\left({ }^{\circ} \mathrm{C}\right.$; dashed curves) from NCAR CESM models, TRMM (no SST plot), and ERA-Interim. Vertical sections in (c) mark the three monsoon developing stages selected: intensification phase (A), heavy rainfall phase $\left(B ;>4 \mathrm{~mm} \mathrm{day}^{-1}\right)$, and weakening phase (C) based on ERA-Interim.

summer period is even more prolonged (until the end of September) in CCSM4 AMIP. This suggests that a large portion of the Arabian Sea rainfall error may arise due to limitations in physical parameterizations employed in the atmospheric model component, consistent with others (e.g., Martin et al. 2010; Ma et al. 2014). The lack of air-sea coupling in the AMIP integration allows the wet bias to be maintained over the Arabian Sea without the compensating feedback of the cold SST biases that tend to suppress the strong convection in the coupled integrations.

\section{3) Monsoon Developing Stages}

As seen in Fig. 2c, the temporal evolution of observed and reanalysis rainfall in the Arabian Sea reveals "three stages" during May-June. For further analysis and model 
specific humidity

(a) ERA-Interim

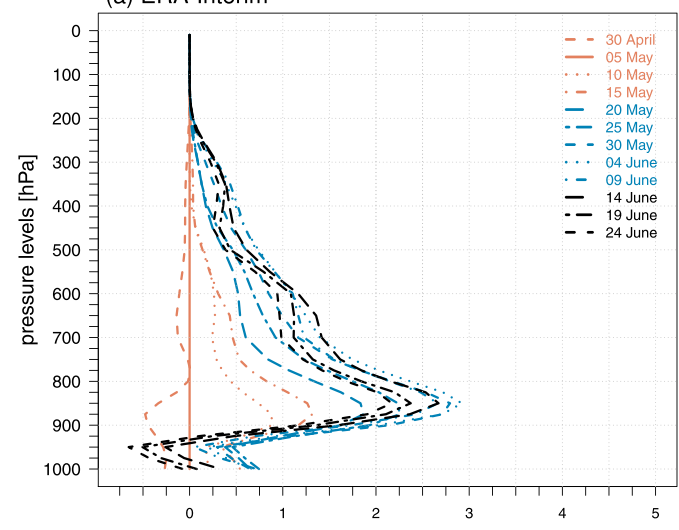

(c) CCSM4

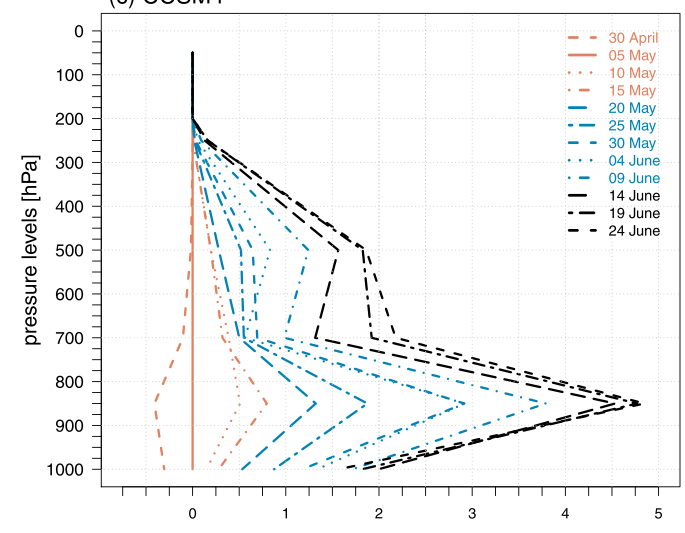

(e) CCSM4 AMIP

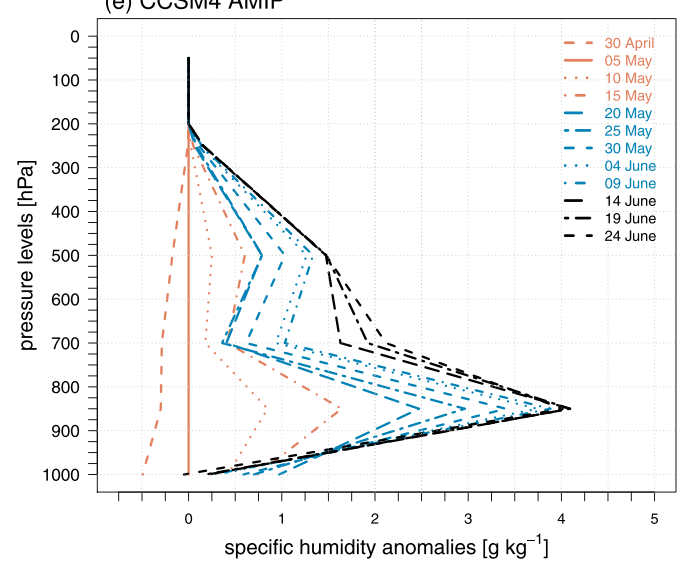

(b) ERA-Interim

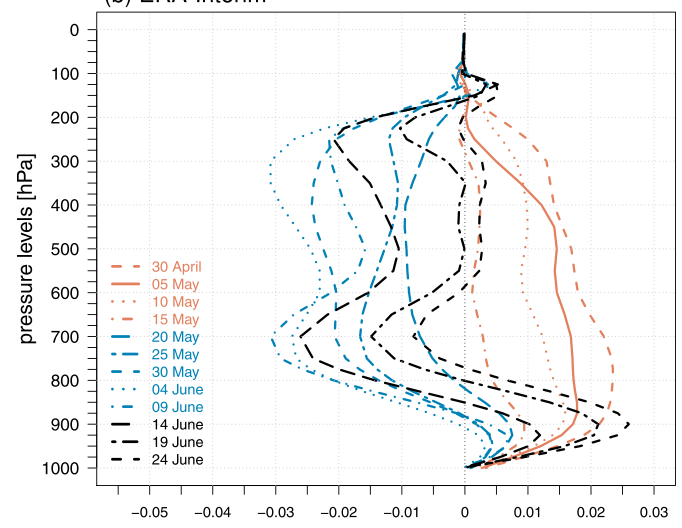

(d) CCSM4
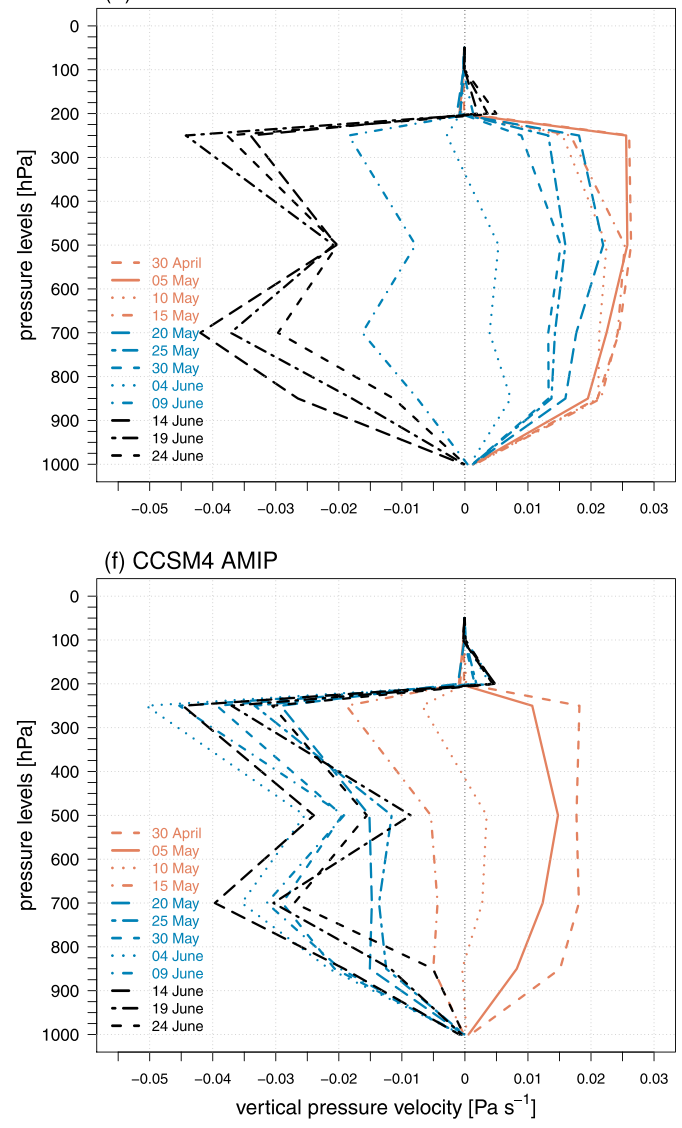

FIG. 3. Vertical structure of 5-day running means of climatological specific humidity anomalies $\left(\mathrm{g} \mathrm{kg}^{-1}\right)$ and vertical pressure velocity $\omega\left(\mathrm{Pa} \mathrm{s}^{-1}\right)$ from (a),(b) ERA-Interim, (c),(d) CCSM4, and (e),(f) CCSM4 AMIP averaged over the Arabian Sea (5$15^{\circ} \mathrm{N}, 52^{\circ}-67^{\circ} \mathrm{E}$ ) during the monsoon developing stages: intensification phase A (red), heavy rainfall phase B (blue), and weakening phase $\mathrm{C}$ (black). For the specific humidity anomalies in (a), (c), and (e), the reference period is centered at 5 May and the vertical profiles are climatological differences between the respective pentads and the reference pentad period.

validation purposes, we split this time window with respect to ERA-Interim into three phases, each 21 days long: an intensification phase (A), a heavy rainfall phase (B) $\left(>4 \mathrm{~mm} \mathrm{day}^{-1}\right)$, and a weakening phase (C) (vertical sections marked as A-C; Fig. 2c). For these three phases, we examine the vertical structure of specific humidity and vertical pressure velocity $\omega$ over our region of interest. In Fig. 3, we compare 5-day running means of climatological 
specific humidity and $\omega$ from ERA-Interim (top) with that from the coupled run of CCSM4 (middle) and CCSM4 AMIP (bottom). Note, for specific humidity, the reference period is centered at 5 May, the transition period from dry to the first heavy rainfall (Fig. 2c), and vertical profiles of moisture in Fig. 3 are climatological differences between the respective pentads and the reference pentad period. The difference plots clearly highlight the buildup and withdrawal of moisture in the vertical, and more importantly indicates systematic errors in the model simulations (e.g., excess moisture in the free troposphere). With regard to vertical pressure velocity, absolute values are shown. Without going into details, we discuss changes in vertical profiles during the intensification and heavy rainfall phases (A and $\mathrm{B}$ ). However, our focus lies during the observed weakening phase (C) when models simulate a wet bias.

In ERA-Interim (Fig. 3a), during phases A (red curves) and B (blue curves), enhanced moisture builds up steadily throughout the troposphere, with a peak around the boundary layer top $(900-800 \mathrm{hPa})$. During these phases, $\omega$ (Fig. 3b) depicts descent throughout initially (red curves) with the transition to weak ascent occurring around 20 May (blue curves). Peak rainfall in phase $\mathrm{B}$ is maintained by abundant moisture, particularly in the free troposphere $\left(>1 \mathrm{~g} \mathrm{~kg}^{-1}\right.$ over $800-550-\mathrm{hPa}$ levels; Fig. 3a), and is associated with a dipole of enhanced $\omega$ showing an upper-level maximum at around $300 \mathrm{hPa}$ and a slightly weaker low-level maximum around $700 \mathrm{hPa}$. This suggests midlevel and elevated latent heating due to congestus clouds and combined effects of deep convection and stratiform clouds during the short-lived high rainfall period (from the end of May to early June), respectively. Our speculation is that the double peaks in $\omega$ profiles (Fig. 3b) imply weaker MSE export out of the column than top-heavy profiles in deep convective regions such as the tropical western Pacific (e.g., Back and Bretherton 2006) due to the very different roles played by top-heavy and bottom-heavy vertical motions in venting MSE. As in the eastern Pacific (Bui et al. 2016), the SST is relatively cool in the Arabian Sea, and in the climatological mean the lower atmosphere is capped by an inversion layer (near-surface descent layer in Fig. 3b) that prevents the convection from deepening during the boreal summer season.

During phases A and B, coupled (Figs. 3c,d) and AMIP-type (Figs. 3e,f) runs broadly capture the temporal evolution in both variables including maximum humidity growth at the boundary layer top and double peaks in $\omega$ but with clear differences among them as well as with reanalysis products. Of relevance here, moisture profile changes in CCSM4 AMIP have close correspondence with ERA-Interim (in agreement with the rainfall evolution in Fig. 2c) but with much stronger intensity in the boundary layer as well as in the free troposphere. Also in CCSM4 AMIP, note that the transition phase, as evidenced by tropospheric descent to ascent, is rather quick and strong. In contrast, in the coupled run, buildup of moisture and signs of ascent are delayed (again, in agreement with rainfall evolution in Fig. 2c) but once established, intensities are higher in both variables.

Relevant to the focus here, the weakening phase $(\mathrm{C}$; black curves) in ERA-Interim (Fig. 3a) is characterized by a gradual reduction of free-tropospheric moisture and a transition to midtropospheric descent (Fig. 3b) suggesting the demise of deep convection. Compared to the earlier phases, in contrast, both model simulations simulate higher moisture in the free troposphere, and deep convection is maintained or increased, as suggested by the persisting double peaks in $\omega$ (Figs. 3d,f). More importantly, ERA-Interim shows the development of relatively dry air (negative differences with respect to the reference period) in the near-surface layer $(1000-900 \mathrm{hPa})$ accompanied by intensifying descent and divergent signatures in the $1000-800-\mathrm{hPa}$ levels, factors that aid to suppress the triggering of convection. In a climatological sense, descent and accompanied warming is associated with a stabilization of the air column and increasing static stability. Diagnostics suggest that such near-surface to boundary layer processes to "turn off" convection are weakly represented in the models. In CCSM4 AMIP, the rather quick and strong transition from tropospheric descent to strong top-heavy ascent (from A to B) and the buildup of excessive moisture in the free troposphere suggest that local processes that stabilize the air column over the Arabian Sea are underestimated in CAM4. In addition to columnbased physical processes, remote effects (i.e., changes in convection and circulation elsewhere) can act to erroneously enhance convection in the models over the Arabian Sea. While possible local processes are identified and discussed next, possible remote effects are discussed later in section $4 \mathrm{~b}(2)$.

\section{b. MSE budget}

In section $2 \mathrm{a}$, temporal evolution of precipitation (Fig. 2c) and its association with vertical profiles of moisture and vertical velocity (Fig. 3) are compared, and certain deficiencies in the model simulations are inferred. However, there is a clear association between precipitation and column moisture in ERA-Interim as well as in the model simulations, paving the way to diagnose the vertically integrated MSE budget [Eq. (5)] to identify processes that contribute to column MSE and hence precipitation, and to identify model biases in MSE 
terms. We average the daily budget terms over the 21 days of phases $B$ and $C$, respectively. To validate our assumption of steady state for the 21-day period during phases $\mathrm{B}$ and $\mathrm{C}$, we estimated $d m / d t$ and also their time averages for the 21-day period for ERA-Interim and the model solutions. In all cases, the storage term fluctuates between $\pm 10 \mathrm{~W} \mathrm{~m}^{2}$ at a daily time scale, and values of their 21-day time averages are within $\pm 4 \mathrm{~W} \mathrm{~m}^{2}\left( \pm 5 \mathrm{~W} \mathrm{~m}^{2}\right)$ for ERA-Interim (the model solutions).

In the MSE budget, positive feedbacks among the terms occur and in a steady-state sense, one expects the budget to close. Various factors including interpolation of data from model levels to standard pressure levels and different advection schemes employed lead to budget residuals. Also, the MSE budget computation from reanalysis has errors and uncertainties (Back and Bretherton 2006) because vertical velocity is not observed but rather inferred from a data assimilation process, which alters the column humidity and temperature. Therefore, a residual component arises in both reanalysis and modeled MSE budgets. However, based on earlier studies (e.g., Neelin and Su 2005; Maloney 2009; Annamalai et al. 2014; Hanf et al. 2017), the leading processes identified are expected to be robust and reproducible. To assess model biases, we point out errors in sources and sinks of column moisture or MSE. In the following, a positive (negative) sign of $-\langle\mathbf{V} \cdot \nabla q\rangle$ represents moist (dry) air advection into the column.

\section{1) ERA-INTERIM}

The analysis of vertically integrated moisture (not shown) and MSE (Fig. 4) budgets from ERA-Interim suggests that, unlike in other deep convective regions such as the Bay of Bengal (not shown), precipitation over the Arabian Sea during phase B is not dominated by a contribution from horizontal moisture convergence but by local high surface evaporation. Note that surface evaporation over the open ocean is determined by the underlying SST and near-surface atmospheric conditions (moisture content, stability, and wind speed). A plausible interpretation is that warm SST in conjunction with increased wind speed during monsoon developing stages results in a higher amount of evaporation. Also, the vertically integrated moisture (not shown) and MSE (Figs. 4a,b) budgets suggest that the demise of rainfall or inhibition of convection during phase $\mathrm{C}$ is associated with a transition from moisture convergence (in phase $\mathrm{B}$ ) to a very weak divergence (in phase C) and a near doubling of the horizontal advection of dry air. Comparing the two phases $\mathrm{B}$ and $\mathrm{C}$ (Figs. 4a,b), there is no change in the contribution of $F_{\text {rad }}$ (sink of MSE), implying the role of dry air advection as the principal sink of MSE for the observed weakening of precipitation over the Arabian Sea.
Identifying the level and timing of this dry air advection and its possible role on convective forcing is of interest here. Therefore, Fig. 5 shows the temporal evolution of the vertical structure of MSE adiabatic terms, including that of temperature advection to infer static stability. Of note is the close association between $-\omega \partial m / \partial p$ (Fig. 5a) and precipitation (Fig. 2c) evolutions. In ERA-Interim (left panels in Fig. 5) in April, advection of moist-warm air above a near-surface layer of dry-cold air advection (Figs. 5b,c) contributes to low-level convective stability measured by negative $-\omega \partial m / \partial p$ (MSE divergence) maximizing at around $925-900 \mathrm{hPa}$ (Fig. 5a). Low-level MSE divergence with weak MSE convergence on top suggests the presence of a near-surface descent layer with shallow convection at the boundary layer top in line with the vertical $\omega$ profiles (curve at 30 April, Fig. 3b). Similar features are noted during most parts of June-July (Fig. 5a) when weak convective activity occurs over the Arabian Sea (cf. Fig. 2c). In early May, horizontal advection of moisture is noticeable in the boundary layer (Fig. 5b), and this term leads the rainfall phase B by few days. During the high rainfall phase $\mathrm{B}, \mathrm{MSE}$ convergence (positive $-\omega \partial \mathrm{m} / \partial p$ ) maximizes at around $825 \mathrm{hPa}$ with simultaneous MSE divergence (negative $-\omega \partial m / \partial p$ ) at $600-200 \mathrm{hPa}$ reflecting enhanced import of MSE at lower levels with MSE export aloft (Fig. 5a), resembling characteristics of an "active convective region" (Houze 1997). But note that even during this period of vigorous convection (phase B), a weak structure of low-level divergence, perhaps due to cold pools induced by downdrafts, is apparent.

The first signature of 1000-900-hPa dry air advection is seen during mid-May; it strengthens and deepens (extending to $800 \mathrm{hPa}$ ) in June-July (Fig. 5b). Around mid- to late May, cold air advection also starts in the near-surface layer with further amplification and vertical extension in June-July (Fig. 5c). Note that in the vertically integrated sense, a weak warm air advection is noted (Figs. 4a,b; left panels), contributed by the intensified warm layer (800-600 hPa) seen in Fig. 5c. Of interest here, during the transition phase from $\mathrm{B}$ to $\mathrm{C}$, cold and dry air advections at $1000-800-\mathrm{hPa}$ levels "lead" the rainfall demise and are interpreted as the leading processes to influence the static stability and trigger the inhibition of convection leading to reduced rainfall $\left(<2 \mathrm{~mm} \mathrm{day}^{-1}\right.$, Fig. 2c). Further, the persistence of warmer air advection on top of the cold-dry air advection until the end of August (not shown) is suggested to be associated with the characteristically dry summer season over the Arabian Sea.

\section{2) Model Simulations}

From a vertically integrated MSE budget perspective, CCSM4 AMIP shows a wet bias during phase B (with respect to ERA-Interim) largely associated with overly 
(a) phase B: heavy rainfall phase


(b) phase C: weakening phase
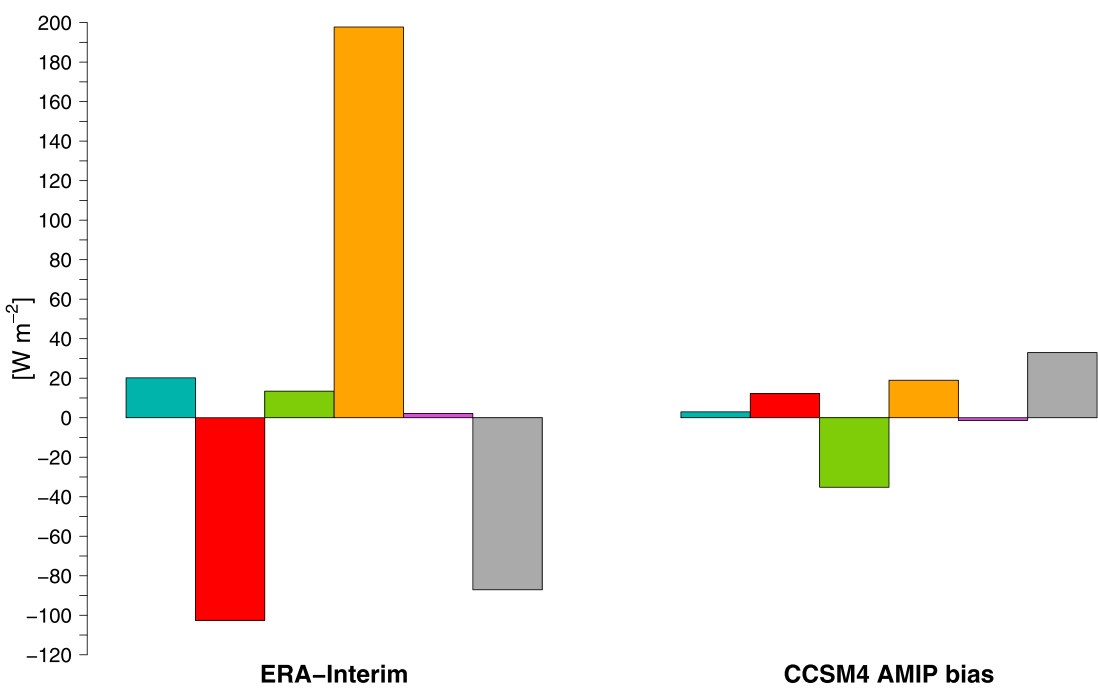

FIG. 4. Mean vertically integrated MSE budget terms $\left(\mathrm{W} \mathrm{m}^{-2}\right)$ averaged over the Arabian Sea $\left(5^{\circ}-15^{\circ} \mathrm{N}, 52^{\circ}-67^{\circ} \mathrm{E}\right)$ for (a) phase $\mathrm{B}$ and (b) phase $\mathrm{C}$ from (left) ERA-Interim and (right) CCSM4 AMIP bias. The budgets are estimated separately for ERA-Interim and CCSM4 AMIP, and then model bias (model minus ERA-Interim) budget terms are calculated.

simulated moisture convergence (or stronger vertical advection; Figs. 3e,f) and enhanced diabatic terms (evaporation and $F_{\text {rad; }}$ right panel in Fig. 4a), although prescribed SST is similar to ERA-Interim. But note that during this particular phase (B), CCSM4 AMIP shows a wet bias only when compared with ERA-Interim, while there is no obvious wet bias against TRMM (Fig. 2c). If one considers the difference between precipitation and other terms as moisture available for "moistening the column" (e.g., Adames and Ming 2018), compared to
ERA-Interim, CCSM4 AMIP has excessive moisture in the free troposphere, as also evidenced in Fig. 3e. The sign of the model biases remains similar in the weakening phase (Fig. 4b; right panel) illustrating the continuation of the wet bias in precipitation. We also examined the budget terms for CCSM4. Salient results include the following: during phase $\mathrm{B}$, the dry bias (delayed monsoon onset) is associated with moisture divergence, underestimation of evaporation (in association with a cold SST bias), and enhanced radiative cooling 
ERA-Interim

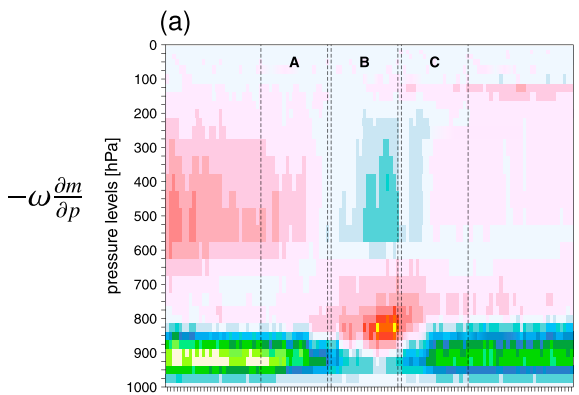

(b)

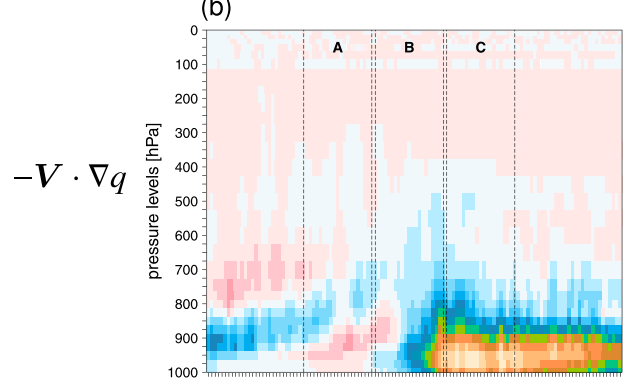

(c)

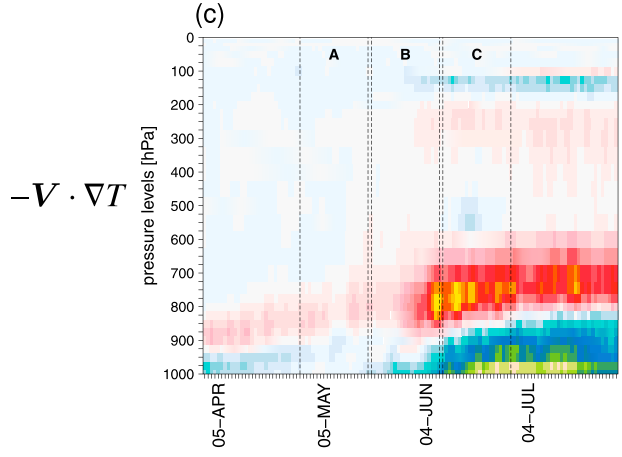

Ccsm4

(d)

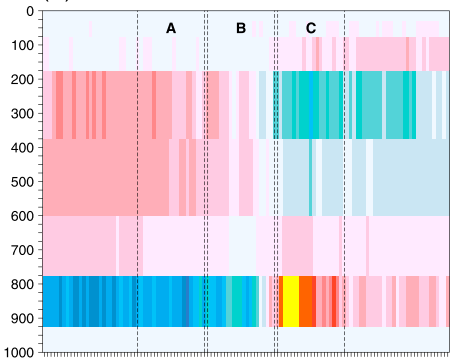

(e)
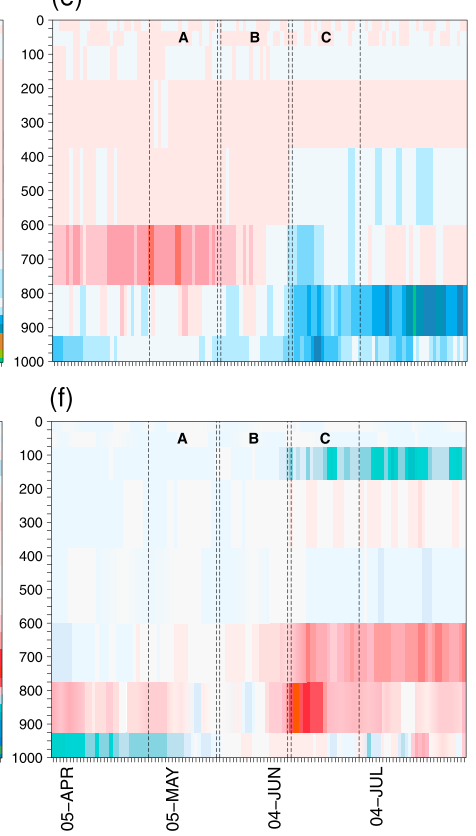

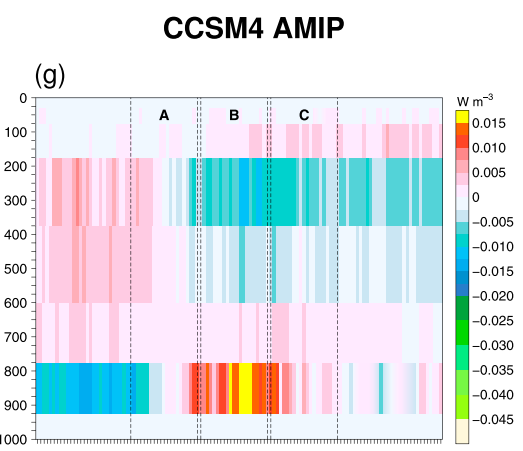

(h)

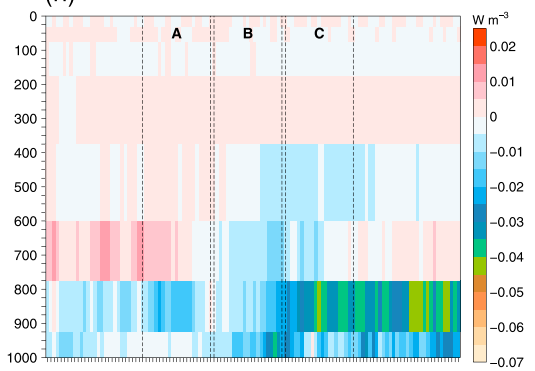

(i)

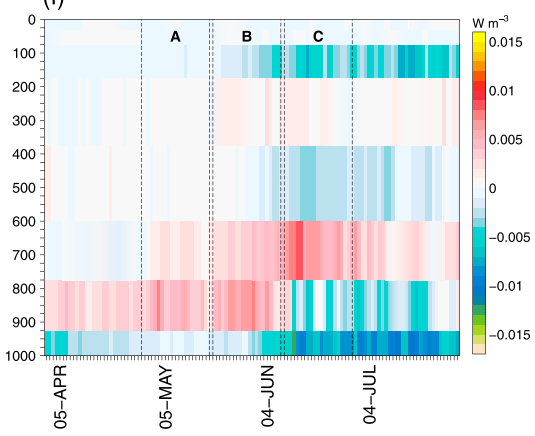

FIG. 5. Daily evolution of vertical cross sections of MSE adiabatic terms $\left(\mathrm{W} \mathrm{m}^{-3}\right)$ averaged over the Arabian $\mathrm{Sea}\left(5^{\circ}-15^{\circ} \mathrm{N}, 52^{\circ}-67^{\circ} \mathrm{E}\right)$ from (a)-(c) ERA-Interim, (d)-(f) CCSM4, and (g)-(i) CCSM4 AMIP during April-July. Vertical sections mark the three phases A (intensification phase), B (heavy rainfall phase), and $\mathrm{C}$ (weakening phase).

despite positive errors in moisture advection; during phase $\mathrm{C}$, the wet bias is associated with overly simulated moisture convergence and positive errors in moisture advection and $F_{\text {rad }}$, despite underestimation of evaporation. Since $F_{\text {rad }}$ is a consequence of convection (e.g., Stephens et al. 2008), here we examine the models' ability in representing horizontal advection terms.

During April, except for the amplitude, both the coupled and uncoupled integrations represent features in all the adiabatic terms reasonably well, and thus the dry premonsoon conditions are adequately captured. As noted in the precipitation evolution (Fig. 2c), low-level MSE divergence in CCSM4 extends well into May (Fig. 5d), suggesting delay in the monsoon developing stages. In early June, CCSM4 simulates a transition to low-level MSE convergence, but unlike in the reanalysis, this feature persists capped with upper-level
MSE divergence until the end of July, implying active convection resulting in a wet bias. Enhanced low-level import of MSE (Fig. 5d) is in line with excess moisture in the PBL (Fig. 3c), and the level of MSE divergence $(\sim 250 \mathrm{hPa}$, Fig. 5d) associated with an upper-level $\omega$ maximum (Fig. 3d) illustrates the depth of convection and/or overestimation of mid-upper-level clouds in the model simulations. Despite the presence of dry air advection in June and thereafter (Fig. 5e), modeled convection and precipitation (Fig. 2c) are maintained. Besides a weaker dry air advection compared to ERA-Interim, CCSM4 fails to represent the cold air advection in the near-surface layer (Fig. 5f).

As noted earlier, CCSM4 AMIP represents the precipitation phase transition from A to B but not from B to C (Fig. 2c). Consistent with that, low-level MSE convergence (Fig. $5 \mathrm{~g}$ ) begins around mid-May and is maintained throughout phase B. As in the reanalysis (Fig. 5b), there 
is a suggestion of dry air advection (Fig. $5 \mathrm{~h}$ ) in the near surface during mid-May with further intensification during June-July. Similarly, CCSM4 AMIP also captures the lowlevel cold air advection in the near-surface levels (Fig. 5i). Compared to ERA-Interim, the timing is well represented, but the intensity of cold and dry air advection is too weak. Therefore, while the precipitation tends to weaken (Fig. 2c) in response to changes in low-level static stability (Figs. 5h,i), its intensity is still $>4 \mathrm{~mm} \mathrm{day}^{-1}$ in June-August.

In summary, process-based diagnostics presented in this section clearly indicate that excessive free-tropospheric moisture is simulated by the model, coupled or uncoupled. Additionally, the model simulations do not adequately represent the near-surface $(1000-800 \mathrm{hPa})$ cold and dry air advection couplet that is expected to inhibit the development of convection over the Arabian Sea. Recent studies have highlighted the importance of insufficient entrainment of environmental air into the cloud convective updrafts (e.g., Del Genio 2012) in causing model precipitation errors. Observations suggest that entrainment of drier air in the lower troposphere makes it more difficult for deep convection to occur than otherwise (Zhang 2009). Comparing CCSM4 and CCSM4AMIP with ERA-Interim (Fig. 5) reveals very weak horizontal advection of dry and cold air in the lower troposphere of the model. In other words, in the vertical 1000-800-hPa air column, during phase $\mathrm{C}$, the air is too moist and warm compared to ERA-Interim. Therefore, we assume that in the 1000-800-hPa levels, entrainment (inflow of environmental air into the cloud updraft) will not be enough to reduce sufficiently the buoyancy of the rising convective plumes and hence to weaken the convection. Note that $\varepsilon(z)$ has a maximum in the lower troposphere (section $2 \mathrm{a}$ ). Therefore, we hypothesize that increasing the entrainment rates will have a larger impact (amplitude) on the dilution of the rising plumes in the lower troposphere (by model construction) leading to buoyancy loss and weakened convection. To test that hypothesis, next we report AMIP-type sensitivity experiments with an increased fractional entrainment rate.

\section{Model sensitivity analysis}

In this section, we first provide an overview of the design of our sensitivity runs with an increased fractional entrainment rate (section 4a). We report on how enhanced entrainment rates impact rainfall evolution over the Arabian Sea [section 4b(1)] followed by the impact over the broader Asian monsoon region [section 4b(2)]. In doing so, we diagnose the impacts on the total precipitation rate as well as on the convective and large-scale components, based on budget diagnostics and vertical structures. We also interpret model simulations with a focus on how enhanced entrainment rate influences sources and sinks of column MSE, cloud-convective characteristics, and hence simulated precipitation patterns.

\section{a. Experiments overview}

A series of sensitivity experiments with increased maximum entrainment rate $\varepsilon_{\max }$ in the dilute CAPE calculation of the deep convection parameterization is performed. In the model, this leads to a decrease in the convective plume CAPE, and subsequently the convection scheme estimates lower instability, eventually leading to a reduction in the cloud-base mass flux and the mean intensity of convection. Similar processes are at work in the Met Office Unified Model studied by Bush et al. (2015). Experiments are conducted with CAM4 with prescribed observed SST from January 1979 to December 1989. We chose CAM4 instead of CAM5 as the atmospheric model component to be consistent with our model diagnostics based on CCSM4 (both coupled and AMIP-type integrations) discussed in section 3. To check if the model response is linear to increased $\varepsilon_{\max }$, we configured three experiments with $\varepsilon_{\max }$ of 1.0 (Control), 2.0 $\left(2 \varepsilon_{\max } \mathrm{EXP}\right)$, and $4.0\left(4 \varepsilon_{\max } \mathrm{EXP}\right)$ so that $\varepsilon_{\max }$ is doubled in each experiment. Simulations are integrated using a finitevolume dynamical core at a horizontal resolution of $1.25^{\circ} \times$ $0.9^{\circ}$ with 26 vertical levels and a physics time step of $1800 \mathrm{~s}$. We found that model precipitation response to a doubling of the entrainment rate is similar to those generated by a quadrupling, but lower in amplitude. For brevity, we show only the results of $4 \varepsilon_{\max }$ EXP.

\section{b. Sensitivity of convection to increased entrainment}

\section{1) ARABIAN SEA}

To assess the effect of enhanced entrainment, we examine the abovementioned experiments first during the monsoon developing stages (May-June) and then discuss the wet bias over the remaining part of the season. Briefly, we show model biases (Control minus ERA-Interim) in the daily evolution of vertical cross sections of specific humidity (Fig. 6a) and cloud fraction (Fig. 7a) and estimated changes due to prescribed enhanced entrainment rates (Figs. $6 \mathrm{~b}$ and $7 \mathrm{~b}$ ). Also shown in Figs. $6 c$ and $7 c$ is the daily evolution of 3-day running means of column water vapor differences and convective and large-scale precipitation rates, respectively. The timing of the heavy rainfall phase (referred to herein as "phase D") and the wet bias phase (referred to herein as "phase E") are based on the convective rainfall evolution in the Control run (solid orange curve, Fig. 7c).

(i)Monsoon developing stages/heavy rainfall phase D. Consistent with the diagnostics presented in section 3, 
(a) Control minus ERA-Interim - specific humidity

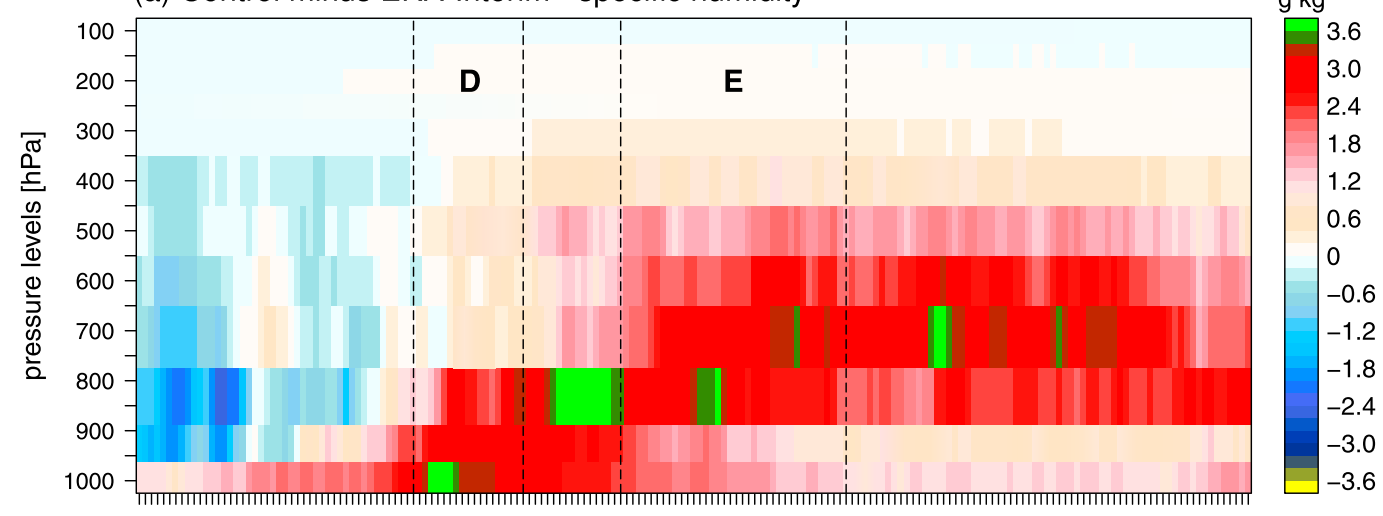

(b) $4 \epsilon_{\max }$ EXP minus Control - specific humidity

$\mathrm{g} \mathrm{kg}^{-1}$

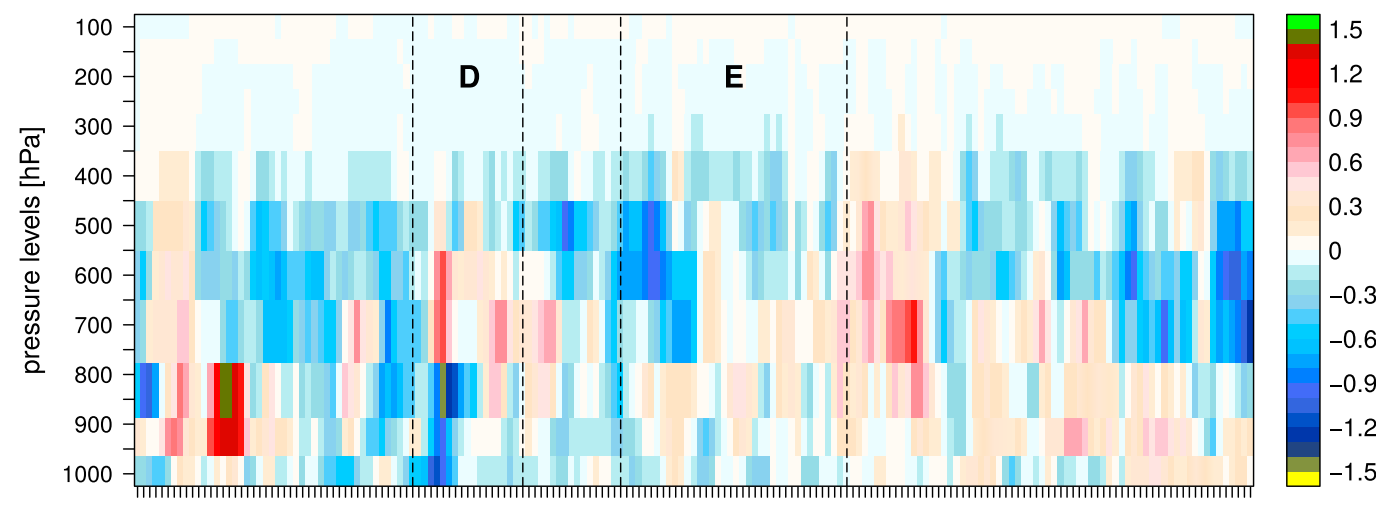

(c) column water vapor



FIG. 6. Daily evolution of vertical cross sections of specific humidity differences $\left(\mathrm{g} \mathrm{kg}^{-1}\right)$ averaged over the Arabian Sea $\left(5^{\circ}-15^{\circ} \mathrm{N}, 52^{\circ}-67^{\circ} \mathrm{E}\right)$ between (a) ERA-Interim and Control run (Control minus ERA-Interim), and (b) Control run and $4 \varepsilon_{\max } \operatorname{EXP}\left(4 \varepsilon_{\max }\right.$ EXP minus Control) during April-September. (c) The 3-day running means of Arabian Sea daily column water vapor differences $(\mathrm{mm})$ for Control minus ERA-Interim (solid curve) and $4 \varepsilon_{\max }$ EXP minus Control (dashed curve). Vertical sections mark phases D (heavy rainfall phase) and $\mathrm{E}$ (wet bias phase) based on the Control run.

model biases in atmospheric moisture are further clear in Figs. 6a and 6c. Briefly, during late April and early May, a wet bias in the PBL and a dry bias in the midtropospheric levels $(\sim 850-400 \mathrm{hPa})$ is associated with a positive bias in low-level clouds (Fig. 7a). Toward the end of May and early June, the wet bias extending through the depth of the troposphere promotes further amplification and vertical extent of the positive cloud bias-all factors favorable for the 
(a) Control minus ERA-Interim - cloud fraction



(b) $4 \epsilon_{\max }$ EXP minus Control - cloud fraction

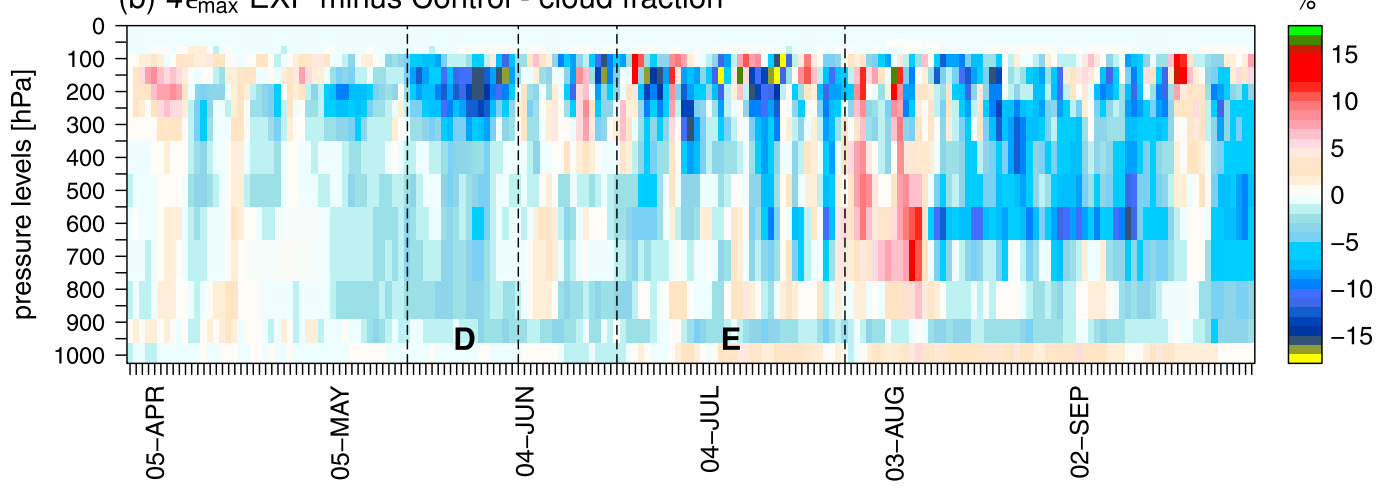

(c) convective and large-scale precipitation



FIG. 7. Daily evolution of vertical cross sections of cloud fraction differences (\%) averaged over the Arabian Sea $\left(5^{\circ}-15^{\circ} \mathrm{N}, 52^{\circ}-67^{\circ} \mathrm{E}\right)$ between (a) ERA-Interim and Control run (Control minus ERA-Interim) and (b) Control run and $4 \varepsilon_{\max } \operatorname{EXP}\left(4 \varepsilon_{\max }\right.$ EXP minus Control) during April-September. (c) The 3-day running means of Arabian Sea daily convective (solid curves) and large-scale (dashed curves) precipitation climatology $\left(\mathrm{mm} \mathrm{day}^{-1}\right)$ from Control (orange) and $4 \varepsilon_{\max }$ EXP (black). Vertical sections mark phases D (heavy rainfall phase) and E (wet bias phase).

occurrence of heavy convective rainfall. A plausible interpretation is as follows: A wet bias in the lower troposphere (PBL) anchors convective instability and triggering of convection, and a gradual transition from dry to wet bias in the mid-upper troposphere (perhaps due to moisture-convection feedbacks) favors overly vertical growth of clouds and resultant heavy rainfall. Note that over open oceans, free-tropospheric moisture content determines precipitation intensity (e.g., Holloway and Neelin 2009). Does enhanced entrainment impact the above-noted biases; particularly, does higher dilution arrest the vertical extent of high clouds?

In response to a higher $\varepsilon_{\max }$, column moisture particularly in the free troposphere is substantially reduced 
during April through mid-May (Fig. 6b) with associated signatures in the vertical growth of clouds (Fig. 7b) and a reduction in convective rainfall (Fig. $7 \mathrm{c}$ ). We interpret the entrainment sensitivity as follows: The combination of a drier (Fig. 6b) and cooler (not shown) lower troposphere will increase the stability of the atmospheric column, a factor that arrests the triggering of convection. During phase $\mathrm{D}$, in combination with drier PBL, cloud fraction is largely reduced in the entire column with largest decline in high-level cloudiness associated with a reduction in the convective rainfall intensity. The heavy rainfall phase $D$ is delayed (Fig. 7c), and 3-day running means of climatological $\omega$ during this phase (not shown) indicate less top-heavy and more dipole-shaped $\omega$ profiles. Together, these results suggest that increasing entrainment delays and reduces peak rainfall over the Arabian Sea and produces a smoother temporal profile of convection (Fig. 7c). However, a closer examination of the specific humidity differences in the 700-500-hPa layer during phase D suggests weak to modest wet conditions relative to the Control run (Fig. 6b).

(ii) Wet bias phase E. As noted earlier (e.g., Fig. 2c), after the monsoon developing stages (May-June), the model simulations exhibit a wet bias in July, a feature that persists throughout the monsoon season. The convective rainfall evolution from the Control run (Fig. 7c) is consistent with that view, and closely follows the total precipitation evolution from CCSM4 AMIP in Fig. 2c. Here, based on the convective rainfall evolution, we term the period mid-June to end of July as the wet bias phase, E. Are there any distinct model characters in the evolution of vertical distribution of specific humidity and associated cloud fraction during the wet bias phase compared to the monsoon developing stages, and if so, how does the entrainment sensitivity experiments handle them?

Nearly 10-12 days after the culmination of phase D, Fig. 6a shows that the model wet bias still prevails predominantly in the PBL but gradually extends through the free troposphere and shows peaks at around $700 \mathrm{hPa}$ during latter part of July. Note that, when compared to ERA-Interim, although the wet bias is prevalent in the PBL during phase $\mathrm{D}$, the wet bias is more pronounced in the free troposphere during phase $\mathrm{E}$, a feature that persists for the rest of the season. One plausible interpretation is that the model convection scheme, in response to instability induced by vertical distribution of temperature (not shown) and low entrainment rates in the Control run, tends to exaggerate the vertical transport of moisture and subsequently anchors development of deep clouds (note cloud bias in the mid-upper levels; Fig. 7a). For most of phase $\mathrm{E}$ and the rest of the season, increasing $\varepsilon_{\max }$ is associated with a drier free troposphere (700-400 hPa, Fig. 6b), a suppressed vertical extension of clouds (Fig. 7b) and subdued convective rainfall activity (Fig. 7c). It is sufficient to mention that over the Arabian Sea, the region where climate models depict a systematic wet precipitation bias (Sperber et al. 2013), our experiments with enhanced entrainment clearly show a notable impact on convective rainfall, and therefore a reduction in the systematic wet error can be expected. We will discuss this in more detail in section $4 \mathrm{~b}(2)$.

(iii) Budget diagnostics for phases $D$ and $E$. To assess the effect of enhanced entrainment on diabatic and adiabatic terms that determine column MSE and subsequently on the simulated precipitation, we examine vertically integrated MSE budgets (Fig. 8) for phases D and $\mathrm{E}$, and also the daily vertical evolution of the adiabatic terms (Fig. 9). To explore the impact on moistureconvection-radiation feedbacks, results presented here need to be compared with the model's biases, particularly CCSM4 AMIP, discussed earlier (Fig. 4).

During phase D, the MSE budget (Fig. 8, left panel) indicates decreased precipitation in association with reduced surface evaporation and net radiative warming (or enhanced radiative cooling) but increased horizontal advection of moisture. Reduced $F_{\text {rad }}$ is indicative of diminished convection and agrees with the analysis of vertical cross sections of specific humidity and cloud fraction (Figs. 6b and 7b). In association with reduced freetropospheric moisture (Fig. 6b), increasing $\varepsilon_{\max }$ produces shallower clouds (Fig. 7b), which are less efficient in trapping upwelling longwave radiation. Diminished convection is expected to reduce column radiative warming (cloud-radiation feedback) leading to additional adiabatic descent, which in turn contributes to a decrease in $-\omega \partial m / \partial p$. The temporal evolution of the vertical $-\omega \partial m / \partial p$ structure (Fig. 9a) clearly shows reduced low-level MSE convergence. Since prescribed SST is identical in both experiments, weakened surface evaporation (Fig. 8, left panel) is perhaps due to weakened surface wind speed or due to moister near-surface atmospheric conditions. Compared with the CCSM4 AMIP wet bias (relative to ERA-Interim) in which diabatic terms such as evaporation and $F_{\text {rad }}$ act as column MSE sources for increased precipitation during phase B (Fig. 4a; right panel), in the entrainment sensitivity experiment these terms turn out to be anomalous sinks of MSE (in a relative sense to Control run) during phase D (Fig. 8, left panel).

During phase $\mathrm{E}$, while decreased precipitation is largely associated with a reduction in horizontal moisture convergence (not shown), increased radiative cooling and reduced moisture advection are the leading anomalous MSE sink terms while surface evaporation tends to 


\section{MSE budget ( $4 \epsilon_{\max }$ EXP minus Control)}

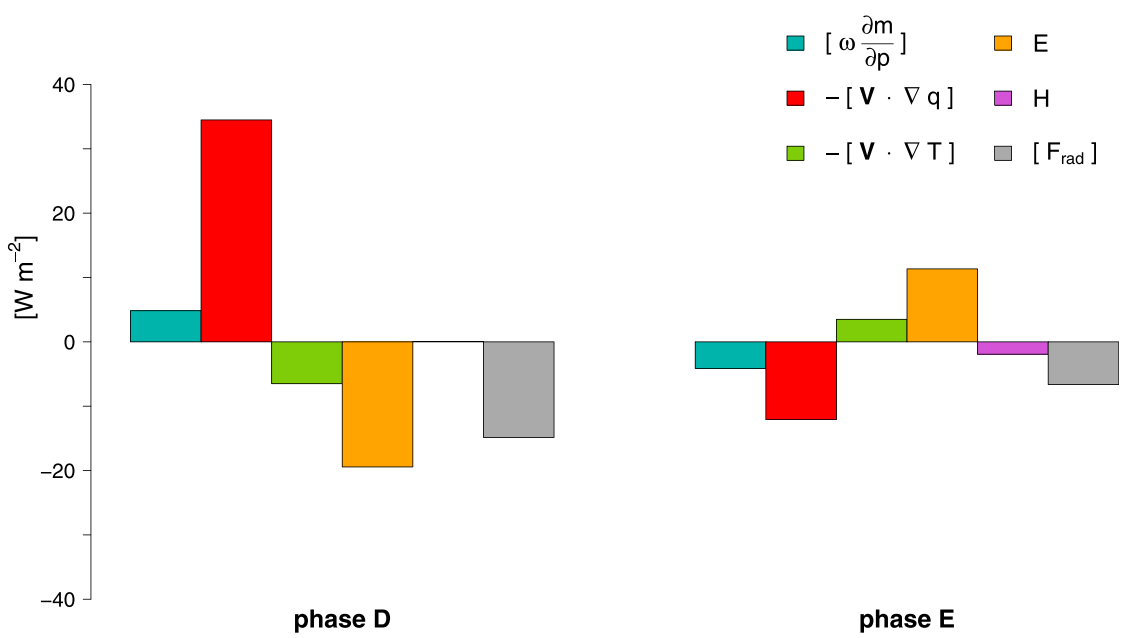

FIG. 8. Mean vertically integrated MSE budget $\left(\mathrm{W} \mathrm{m}^{-2}\right)$ averaged over the Arabian Sea $\left(5^{\circ}-15^{\circ} \mathrm{N}, 52^{\circ}-67^{\circ} \mathrm{E}\right)$ for (left) phase $\mathrm{D}$ and (right) phase E from $4 \varepsilon_{\max }$ EXP minus Control. The budgets are estimated separately for the Control run and $4 \varepsilon_{\max } \mathrm{EXP}$, and then difference budget terms are calculated.

oppose these (Fig. 8, right panel). For comparison, the wet bias in CCSM4 AMIP is dominated by enhanced moisture advection, evaporation, and net radiative warming during phase $\mathrm{C}$ (Fig. $4 \mathrm{~b}$; right panel). Reduced precipitation during phase $\mathrm{E}$ is consistent with reduced low-level MSE convergence and horizontal temperature advection noted in the vertical plots (Fig. 9). Increased horizontal advection of moisture that is prevalent in the PBL during late April and early May is noticeable in the free troposphere during phase D (Fig. 9b). But note that during phase $\mathrm{E}$, there is a reduction in moist and warm air advection in the PBL indicative of a more stable convective environment that is associated with inhibited vertical cloud growth (Fig. 7b) and a reduced convective rain rate (Fig. 7c). In summary, in both phases $\mathrm{D}$ and $\mathrm{E}$, enhanced $\varepsilon_{\max }$ in CAM4 produces reduced convective activities in association with weakened moisture-convection and cloudradiation feedbacks. In the sensitivity experiments, apart from column-based physical processes, remotely forced descent also contributes to the precipitation reduction over the Arabian Sea. Possible remote effects are discussed next in section $4 \mathrm{~b}(2)$.

\section{2) BROADER ASIAN MONSOON REGION}

Figure 10 plots the changes in the mean JuneSeptember (JJAS) spatial pattern of total precipitation and horizontal wind at $850 \mathrm{hPa}$ (Fig. 10a), convective precipitation (Fig. 10c), and large-scale precipitation over the broader Asian monsoon region to globally increased $\varepsilon_{\max }$ (Fig. 10d). We also show model biases of total precipitation and $850-\mathrm{hPa}$ horizontal wind vectors for the
Control run with respect to observations/reanalysis in Fig. 10b. Briefly, total precipitation decreases over two broad regions covering $10^{\circ} \mathrm{S}-0^{\circ}, 40^{\circ}-140^{\circ} \mathrm{E}$ and $10^{\circ}-35^{\circ} \mathrm{N}$, $40^{\circ}-70^{\circ} \mathrm{E}$ with largest reductions over the eastern Arabian Sea (Fig. 10a). Of relevance here, total decreased precipitation patterns are predominantly contributed by convective precipitation (Fig. 10c). In contrast, precipitation increases over the region $10^{\circ}-30^{\circ} \mathrm{N}, 70^{\circ}-160^{\circ} \mathrm{E}$ with a local maximum over the plains of Indochina, and the entire pattern is predominantly contributed by the large-scale component (Fig. 10d) with modest contribution from the convective component as well (Fig. 10c). Relative to Control, $4 \varepsilon_{\max }$ EXP alters the mean horizontal low-level wind field over the region $10^{\circ}-30^{\circ} \mathrm{N}, 70^{\circ}-160^{\circ} \mathrm{E}$ with enhanced westerlies particularly over mainland Southeast Asia improving the easterly wind bias in this region (cf. wind vectors in Figs. 10a and 10b). Broadly speaking, entrainment sensitivity results in redistribution of precipitation over the broader monsoon region as well as precipitation partitioning and changes to local circulation features.

Annamalai et al. (2017) interpreted that low-level convergence driven by the positive precipitation error (wet bias) in the Arabian Sea weakens the cross-equatorial moisture transport into South Asia, thereby weakening the monsoon precipitation over India, the Bay of Bengal, and the tropical west Pacific, which further reduces the lowlevel cross-equatorial flow into the Arabian Sea (the Findlater jet) via Rossby wave response. The bias plot in Fig. 10b clearly demonstrates enhanced (suppressed) precipitation over the Arabian Sea (central-eastern equatorial 

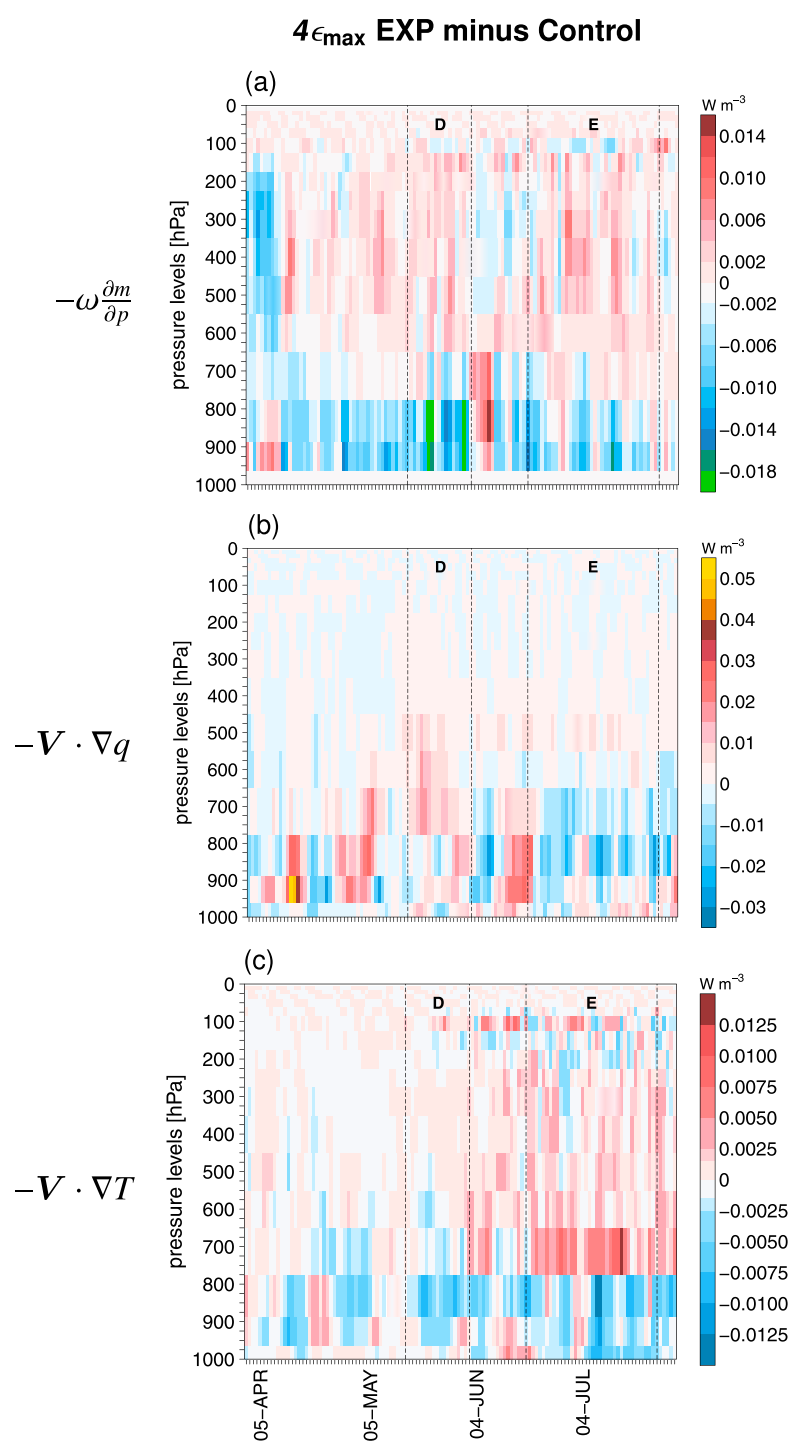

FIG. 9. Daily evolution of vertical cross sections of MSE adiabatic terms $\left(\mathrm{W} \mathrm{m}^{-3}\right)$ averaged over the Arabian Sea $\left(5^{\circ}-15^{\circ} \mathrm{N}, 52^{\circ}-67^{\circ} \mathrm{E}\right)$ from $4 \varepsilon_{\max }$ EXP minus Control during April-July. The budget terms are estimated separately for the Control run and $4 \varepsilon_{\max }$ EXP, and then difference budget terms are calculated. Vertical sections mark phases D (heavy rainfall phase) and $\mathrm{E}$ (wet bias phase).

Indian Ocean). In response to that forcing, a Rossby wave response is generated with cyclonic (anticyclonic) relative vorticity to the north-northwest of the wet bias in the Arabian Sea (to the southwest of the dry bias in the southern Indian Ocean), which in turn is expected to weaken the Findlater jet. A suppression of the wet (dry) bias over the Arabian Sea (central-eastern equatorial Indian Ocean) in $4 \varepsilon_{\max }$ EXP (Fig. 10a) then allows moisture transport by the low-level westerlies to reach the region $10^{\circ}-30^{\circ} \mathrm{N}, 70^{\circ}-160^{\circ} \mathrm{E}$. We hypothesize that the increase in convective rainfall over the plains of Indochina and the tropical west Pacific is associated with this increased moisture convergence. Precipitation partitioning depends on the model's cumulus parameterization. While higher $\varepsilon_{\max }$ inhibits convective precipitation, large-scale precipitation increases over the broader Asian monsoon region. Similar results are noted in other modeling studies (e.g., Zhao et al. 2018b). The redistribution of precipitation impacts local circulation features and also contributes to suppressed precipitation pattern. For example, diabatic heating associated with increased precipitation over the Indochina-tropical west Pacific would (i) induce a Rossby wave pattern to the west with implied subsidence over the Arabian Sea-Arabian Peninsular regions (Rodwell and Hoskins 1995; Annamalai and Sperber 2005) and (ii) force a local Hadley-type circulation with descent over the southern Indian Ocean-Maritime Continent latitudes. Specifically, in an equilibrium response diagnosed here, local and remote feedbacks are involved in the final outcome. To assess the possible role of increased precipitation over the Indo-Pacific-west Pacific on suppressed precipitation over the Arabian Sea, Fig. 10e shows anomalous east-west vertical circulation averaged over $10^{\circ}-25^{\circ} \mathrm{N}$. The anomalous ascent over the longitudes of increased precipitation appears to be connected to the anomalous descent over the Arabian Sea longitudes.

Despite several improvements in the simulation of the mean boreal summer precipitation pattern over the Asian monsoon region, a higher $\varepsilon_{\max }$ does not effectively reduce all seasonal precipitation biases; for example, dry biases in the equatorial eastern Indian Ocean and in the Sea of Japan-East China Sea region (cf. Figs. 10a,b). Increasing $\varepsilon_{\max }$ even intensifies the wet bias over the Western Ghats, likely because of enhanced low-level westerlies transporting more moisture into India. This is consistent with results from Bush et al. (2015), who found that the characteristics of the air of the surrounding environment play a role in local feedbacks to increased entrainment. In summary, our sensitivity experiments demonstrate that insufficient entrainment in CAM4 is only one cause of the systematic errors over the Asian monsoon region. In other parts of the tropics, a higher $\varepsilon_{\max }$ has also an effect on the mean state (not shown). The $4 \varepsilon_{\max }$ EXP shows a beneficial decrease in precipitation along the South Pacific convergence zone and an improvement in the double ITCZ bias in agreement with previous studies (e.g., Oueslati and Bellon 2013; Hirota et al. 2014). Other improved aspects of the mean state include ITCZs in the east-equatorial Pacific and along the equatorial Atlantic, and the West African monsoon. Though beneficial, enhanced entrainment shows detrimental effects in other fields such as cold bias in the upper troposphere, jet stream intensity, and tropopause 

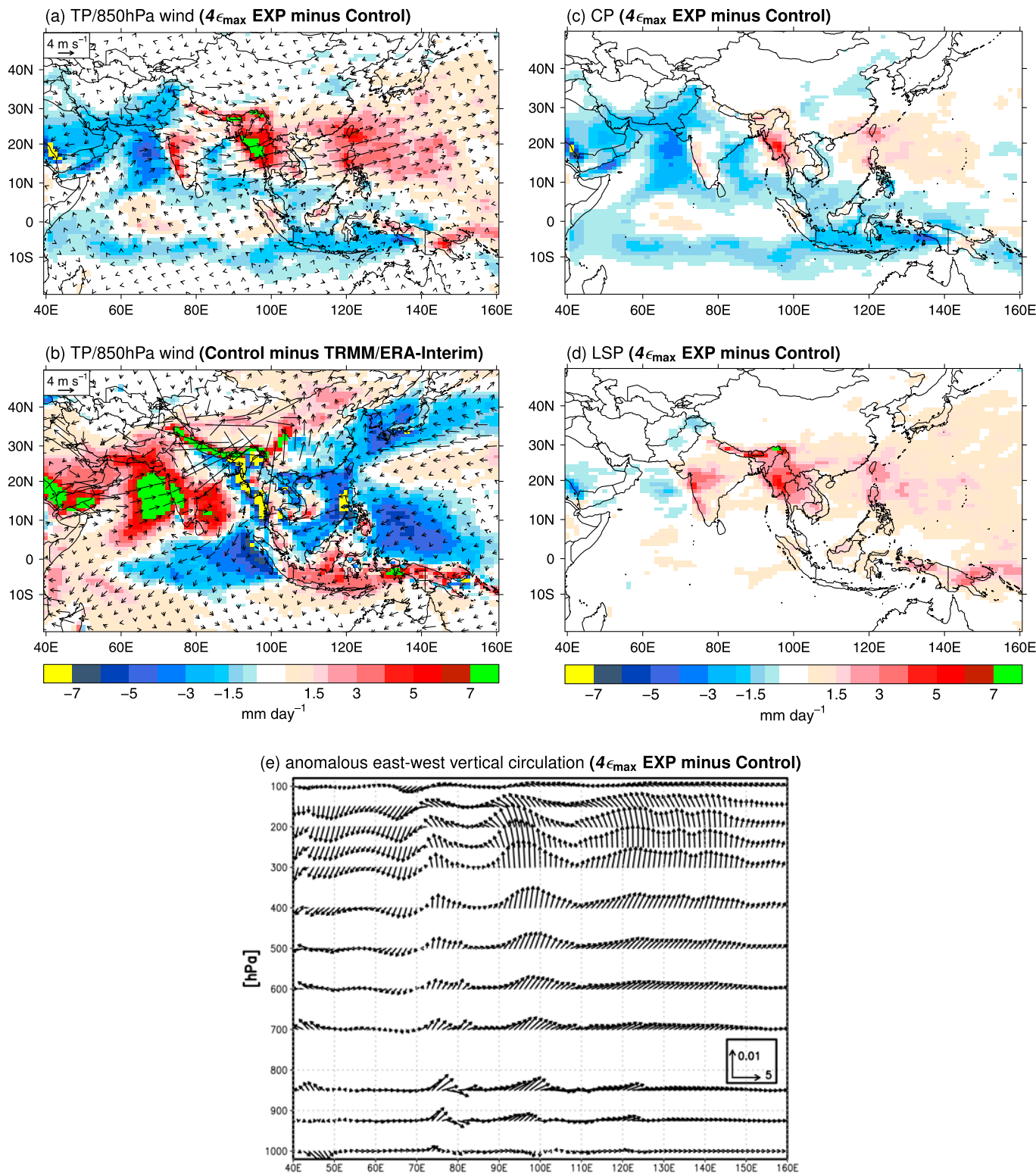

FIG. 10. June-September averaged climatology differences for (a) total precipitation ( $\mathrm{mm} \mathrm{day}^{-1}$ ) and 850 -hPa horizontal wind vectors $\left(\mathrm{m} \mathrm{s}^{-1}\right)$, (c) convective precipitation $\left(\mathrm{mm} \mathrm{day}^{-1}\right)$, and $(\mathrm{d})$ large-scale precipitation $\left(\mathrm{mm} \mathrm{day}^{-1}\right)$ from $4 \varepsilon_{\max }$ EXP minus Control. (b) Model biases of total precipitation $\left(\mathrm{mm} \mathrm{day}^{-1}\right.$ ) and 850-hPa horizontal wind vectors $\left(\mathrm{m} \mathrm{s}^{-1}\right)$ for the Control run with respect to observations/reanalysis (Control minus TRMM/ERA-Interim). (e) Anomalous eastwest vertical circulation averaged over $10^{\circ}-25^{\circ} \mathrm{N}$ for $4 \varepsilon_{\max }$ EXP minus Control.

height (not shown). These aspects are consistent with Bush et al. (2015) and Chen and Mapes (2018).

\section{Summary and discussion}

\section{a. Summary}

In continuing efforts to identify and isolate model errors during the boreal summer season of the Asian monsoon, the present study applied process-based diagnostics to NCAR climate models and reanalysis products with a focus on the monsoon developing stages (May-June). We developed a working hypothesis and performed idealized sensitivity experiments to test that hypothesis.

Observations/ERA-Interim show that in early May, the Arabian Sea is characterized by a "sudden burst" of rainfall, followed by a short-lived high rainfall period $\left(>4 \mathrm{~mm} \mathrm{day}^{-1}\right)$ of a duration of less than a month, and the demise of rainfall activity thereafter. During May-June, temporal evolution of vertical profiles of moisture and $\omega$ highlight the buildup (from the PBL to free troposphere) 
and withdrawal of moisture, and the transition of bottomheavy to top-heavy $\omega$ patterns and to midlevel descent in $\omega$ structures, respectively. Whereas model simulations capture these transitions, both coupled and AMIP-type integrations of CCSM4 do not represent the weakening phase characteristics; instead, they simulate excess freetropospheric moisture and top-heavy $\omega$ patterns that are illustrative of continued wet conditions. To identify the leading processes that determine the rainfall characteristics over the Arabian Sea, we diagnosed moisture and MSE budgets. The budget analysis indicated that in ERAInterim near-surface cold and dry air advection leads the observed demise of rainfall activity in early June. We interpret these terms as the leading processes to influence static stability and convective inhibition. In contrast, the model simulations show excess moisture convergence and moisture advection as well as warming biases in $F_{\text {rad }}$ at that time. Overall, the process-based diagnostics suggest two primary factors for the persistence of the wet bias in the model simulations: (i) excessive free-tropospheric moisture and (ii) underestimation of the near-surface cold-dry air advection couplet. We argued that both these factors in conjunction with cloud-radiative feedbacks (biases in $F_{\text {rad }}$ and mid-upper-tropospheric clouds) and positive feedbacks between adiabatic and diabatic terms can increase column diabatic heating, and thereby reinforce preexisting vertical motion and convergence.

In light of the severity of the persistent wet bias over the Arabian Sea and motivated by numerous earlier studies that demonstrated the sensitivity of GCMs to entrainment (e.g., Hannah and Maloney 2011; Del Genio 2012; Bush et al. 2015; Zhao et al. 2018a,b), we performed AMIP-type sensitivity experiments with CAM4 to explore the effect of enhanced environmental mixing on the model's wet bias. Globally increasing the maximum entrainment rate clearly reduces column moisture, especially in the free troposphere over the Arabian Sea during the monsoon developing stages and the heavy rainfall phase. Higher $\varepsilon_{\max }$ arrests the vertical extension of clouds and leads to reduced convective rainfall. These model features associated with enhanced $\varepsilon_{\max }$ continue during the rest of the season in association with a suppression of the wet bias. Budget diagnostics suggest reductions in longwave warming and moisture advection, which act as sinks of column MSE. Further, diminished low-level MSE convergence and reduced low-level warmmoist air advection are factors unfavorable for the triggering of convection. Apart from local effects, remotely forced descent also contributes to reduction in precipitation over the Arabian Sea.

\section{b. Discussion}

Diagnostics performed here suggest that horizontal advection of the low-level cold and dry air couplet is the leading candidate for the observed precipitation weakening that the model simulations underestimate over the Arabian Sea in early June. What is the source of this cold-dry air couplet? Could it be the upwelling regions along the Somalia-Arabia coasts? Focusing on May-June, ERA-Interim results shown in Fig. 11 provide a summary to these questions. During the heavy rainfall phase (phase B over the Arabian Sea), due to evaporative cooling, lower SST is observed along the low-level monsoon flow (Fig. 11a). The intense cooling tendency, which is greatest along Somalia's coast (SST tendency $<-1.0 \mathrm{~K} \mathrm{~s}^{-1} \times 10^{-6}$, red dotted region in Fig. 11a), is due to upwelling of cold subsurface waters by the alongshore-meridional component of the low-level Findlater jet (e.g., McCreary et al. 1993). Time series of a few variables of relevance to the discussion and averaged over this red-dotted region (referred to herein as the "Somalia Coast") are shown in Fig. 11b from ERAInterim (light blue), CCSM4 (dark brown), and CCSM4 AMIP (orange).

In ERA-Interim (light blue, Fig. 11b), in early to midMay, SST remains high $\left(>29^{\circ} \mathrm{C}\right)$, low-level winds and associated surface evaporation increase in time and so do the boundary layer temperature and specific humidity in the Somalia Coast region. At this time, rainfall as measured by ERA-Interim rises from 2 to $4 \mathrm{~mm} \mathrm{day}^{-1}$ over the Arabian Sea, which is a precursor for the heavy rainfall phase there. At the Somalia Coast, once the wind speed exceeds about $5 \mathrm{~m} \mathrm{~s}^{-1}$ around mid-May, SST drops. There appears to be an inverse relationship between the two variables, confirming an earlier finding that the intensity of cold upwelling off the coast of Somalia is largely dictated by the alongshore wind speed (McCreary et al. 1993). Despite SST cooling, surface evaporation continues to increase as wind speed increases. Within a few days of the SST cooling initiating, the boundary layer temperature and specific humidity begins to drop (around 20 May), since colder air holds less moisture. In other words, in response to increasing wind speed, SST drops to below $27^{\circ} \mathrm{C}$ around 10 June, and subsequently the $1000-850-\mathrm{hPa}$ air above this cold pool becomes cool and very dry (and less conducive for convection). Climatologically, under the influence of the Coriolis force, low-level cross-equatorial flow becomes westerly over the Arabian Sea (Fig. 11a), which is extremely effective in advecting offshore the "drycold air couplet." The focus region's (boxed area in Fig. 2b) close proximity to the Somalia Coast region means that it receives the "dry-cold air couplet" with little opportunity for dilution. Thus, this advection process helps to "shut off" convection there. Our findings here, with emphasis on "local air-sea interaction processes," deserve attention to make progress in monsoon modeling. 
(a) mean SST tendency / 850hPa wind phase B (ERA-Interim)

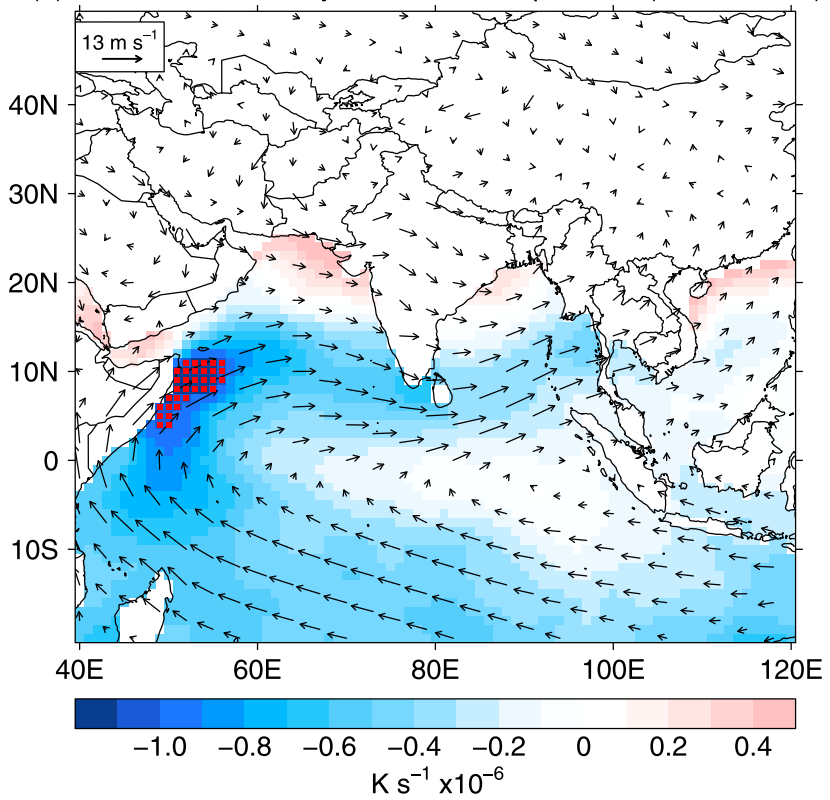

(b) coupled processes in upwelling region (Somalia Coast)

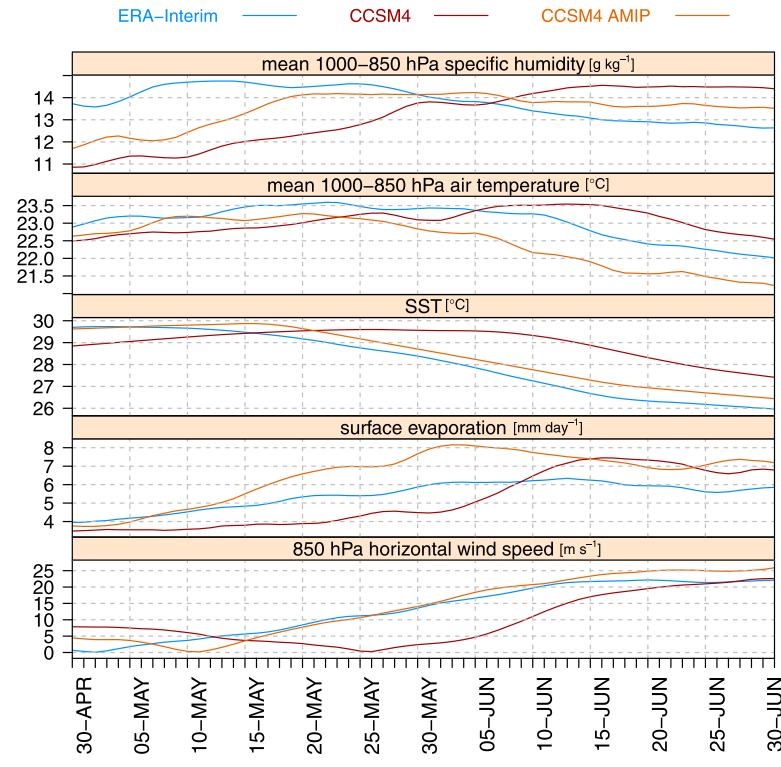

FIG. 11. (a) Mean SST tendency ( $\mathrm{K} \mathrm{s}^{-1}$; shading) and mean 850-hPa horizontal wind ( $\mathrm{m} \mathrm{s}^{-1}$; arrows) from ERA-Interim during phase B. Units of SST tendency are in $\mathrm{K} \mathrm{s}^{-1} \times 10^{-6}\left(\mathrm{~K}\right.$ day $\left.^{-1} / 86400\right)$ so that around $-1.0 \mathrm{~K} \mathrm{~s}^{-1} \times 10^{-6}$ corresponds to around $-8.6 \mathrm{~K}^{-1 a y}{ }^{-1} \times 10^{-2}$. The red-dotted region (Somalia Coast) marks the region of intense SST cooling (SST tendency $<-1.0 \mathrm{~K} \mathrm{~s}^{-1} \times 10^{-6}$ ) during phase B. (b) Time series of relevant variables from ERA-Interim (light blue), CCSM4 (dark brown), and CCSM4 AMIP (orange) averaged over the Somalia Coast (red-dotted region in Fig. 11a) during the monsoon developing stages.

Realistic representation of boundary layer processes off Somalia's coast during and after monsoon onset stages appears important in reducing the systematic errors over the western Indian Ocean-Arabian Sea. In the NCAR family models diagnosed here, the monsoon onset is delayed in the coupled CCSM4 version (around 8-10 June), and therefore SST cooling off Somalia and subsequent response in $1000-850-\mathrm{hPa}$ averaged air temperature are also delayed (brown graphs, Fig. 11b), but there is no sign of weakening of the $1000-850-\mathrm{hPa}$ averaged specific humidity (brown graphs, Fig. 11b). Similarly, in the SST prescribed CCSM4 AMIP run, insufficient specific humidity (1000-850-hPa averaged) response to SST cooling is noted along with higher surface evaporation (orange graphs, Fig. 11b). In summary, our results suggest insufficient sensitivity of modeled PBL humidity to changes in SST off Somalia's coast in CAM4. A closer examination of the SST evolution between ERA-Interim and CCSM4 AMIP (Fig. 11b) further reveals that the CCSM4 AMIP run SSTs are up to $0.5 \mathrm{~K}$ higher than those in the ERA-Interim during MayJune. This can contribute to the insufficient decrease in specific humidity in the 1000-850-hPa layer in CCSM4 AMIP. Monthly SST values are interpolated to daily values to force the model in the AMIP-type runs reported here. It will be worthwhile to check the validity of the results presented here if observed daily SST is used as forcing.
Unlike in other deep convection regions, such as the Bay of Bengal, moisture budget diagnostics estimated from ERA-Interim show that horizontal moisture convergence is not the dominant term in determining precipitation over the Arabian Sea. For example, during the heavy rainfall phase $\mathrm{B}$, the axis of the low-level jet lies around $7^{\circ}-8^{\circ} \mathrm{N}$ (Fig. 11a) and, due to shear vorticity, anticyclonic (cyclonic) relative vorticity and associated divergence (convergence) prevails south (north) of the axis. This pattern reduces net convergence. Both model simulations that we examined have a bias in horizontal moisture convergence over the Arabian Sea, which is likely attributable to misrepresentation of the latitudinal location of the low-level jet axis (not shown). Based on idealized modeling studies, Rodwell and Hoskins (1995) suggested that realistic representation of the East African mountains and a land-sea contrast in surface friction are important factors in the existence and concentration of the monsoon cross-equatorial flow, as well as the associated jetlike features. Furthermore, the intensity of the colddry air advection couplet depends on the intensity of upwelling and local coupled processes that are themselves influenced by cross-equatorial winds. While enhanced entrainment is a factor in reducing the wet bias, sensitivity of the cross-equatorial flow characteristics (particularly during May-June) to PBL processes and 
the representation of orography remain to be assessed with climate models.

The approach adopted here has many similarities and some differences with recent studies of Bush et al. (2015) and Zhao et al. (2018a,b). Of the similarities, all the three studies tested the effect of increased entrainment in modeled monsoon precipitation and note a reduction in the wet bias over the Arabian Sea but an increase in the wet bias over the tropical western Pacific, that is, a consistent pattern irrespective of different convection schemes and differing approaches of mixing. Of the differences, our primary focus is to apply process-based diagnostics and identify leading processes that anchor the demise of monsoon precipitation over the Arabian Sea after the initial burst of heavy rainfall during late May and early June. Our diagnostics indicate that lower-tropospheric levels in the model do not adequately represent the formation of, and response to, cold SST off Somalia coasts, and further work is needed to ascertain the relative and combined roles of PBL resolution and representation of PBL processes to confirm the importance of the cold-dry air couplet in impacting the demise of convection over the Arabian Sea.

Acknowledgments. The authors appreciate many thoughtful and constructive comments and critics from three anonymous reviewers that improved the manuscript. We sincerely thank Richard Neale from NCAR for fruitful discussions on model entrainment and detrainment processes. This study is supported from the National Science Foundation (NSF) under Grant 1460742. $\mathrm{H}$. Annamalai also acknowledges the support from NOAAMAPP funding NA15OAR4310092. The authors express sincere gratitude to Jan Hafner for his support in setting up the CAM4 simulations. Sensitivity experiments were performed at the Climate and Global Dynamics Lab Office (CGD-NCAR, Boulder). For data access, please contact franziska.hanf@uni-hamburg.de. We thank the ECMWF for providing the ERA-Interim reanalysis products. CMIP5 data analyzed here (CCSM4, CCSM4 AMIP, and CESM1-CAM5) are provided by the Earth System Grid Federation (ESGF). We also acknowledge the NASA Goddard Earth Sciences Data and Information Services Center (GES DISC) for making the TRMM satellite data used in this study freely available (https:// mirador.gsfc.nasa.gov/).

\section{REFERENCES}

Adames, A. F., and Y. Ming, 2018: Moisture and moist static energy budgets of South Asian monsoon low pressure systems in GFDL AM4.0. J. Atmos. Sci., 75, 2107-2123, https://doi.org/ 10.1175/JAS-D-17-0309.1.

Adler, R. F., and Coauthors, 2003: The version-2 Global Precipitation Climatology Project (GPCP) monthly precipitation analysis (1979-present). J. Hydrometeor., 4, 1147-1167, https://doi.org/ 10.1175/1525-7541(2003)004<1147:TVGPCP $>2.0$. CO 2 .

Annamalai, H., and K. R. Sperber, 2005: Regional heat sources and the active and break phases of boreal summer intraseasonal (30-50 day) variability. J. Atmos. Sci., 62, 2726-2748, https:// doi.org/10.1175/JAS3504.1.

_ , J. M. Slingo, K. R. Sperber, and K. Hodge, 1999: The mean evolution and variability of the Asian summer monsoon: Comparison of ECMWF and NCEP-NCAR reanalyses. Mon. Wea. Rev., 127, 1157-1186, https://doi.org/10.1175/1520-0493(1999)127<1157: TMEAVO $>2.0 . \mathrm{CO} ; 2$.

_ J. Hafner, A. Kumar, and H. Wang, 2014: A framework for dynamical seasonal prediction of precipitation over the Pacific Islands. J. Climate, 27, 3272-3297, https://doi.org/10.1175/ JCLI-D-13-00379.1.

—, B. Taguchi, J. P. McCreary, M. Nagura, and T. Miyama, 2017: Systematic errors in South Asian monsoon simulation: Importance of equatorial Indian Ocean processes. J. Climate, 30, 8159-8178, https://doi.org/10.1175/JCLI-D-16-0573.1.

Back, L. E., and C. S. Bretherton, 2006: Geographic variability in the export of moist static energy and vertical motion profiles in the tropical Pacific. Geophys. Res. Lett., 33, L17810, https:// doi.org/10.1029/2006GL026672.

Bechtold, P., M. Köhler, T. Jung, F. Doblas-Reyes, M. Leutbecher, M. J. Rodwell, F. Vitart, and G. Balsamo, 2008: Advances in simulating atmospheric variability with the ECMWF model: From synoptic to decadal time-scales. Quart. J. Roy. Meteor. Soc., 134, 1337-1351, https://doi.org/10.1002/qj.289.

Boos, W. R., and J. V. Hurley, 2013: Thermodynamic bias in the multimodel mean boreal summer monsoon. J. Climate, 26, 2279-2287, https://doi.org/10.1175/JCLI-D-12-00493.1.

Bretherton, C. S., M. E. Peters, and L. E. Back, 2004: Relationships between water vapor path and precipitation over the tropical oceans. J. Climate, 17, 1517-1528, https://doi.org/10.1175/15200442(2004)017<1517:RBWVPA $>2.0$.CO;2.

— P. N. Blossey, and M. E. Peters, 2006: Interpretation of simple and cloud-resolving simulations of moist convection-radiation interaction with a mock-Walker circulation. Theor. Comput. Fluid Dyn., 20, 421-442, https://doi.org/10.1007/s00162-006-0029-7.

Bui, H. X., J.-Y. Yu, and C. Chou, 2016: Impacts of vertical structure of large-scale vertical motion in tropical climate: Moist static energy framework. J. Atmos. Sci., 73, 4427-4437, https://doi.org/10.1175/JAS-D-16-0031.1.

Bush, S. J., A. G. Turner, S. J. Woolnough, G. M. Martin, and N. P. Klingaman, 2015: The effect of increased convective entrainment on Asian monsoon biases in the MetUM general circulation model. Quart. J. Roy. Meteor. Soc., 141, 311-326, https:// doi.org/10.1002/qj.2371.

Chen, B., and B. E. Mapes, 2018: Effects of a simple convective organization scheme in a two-plume GCM. J. Adv. Model. Earth Syst., 10, 867-880, https://doi.org/10.1002/2017MS001106.

Dee, D. P., and Coauthors, 2011: The ERA-Interim reanalysis: Configuration and performance of the data assimilation system. Quart. J. Roy. Meteor. Soc., 13, 553-597, https://doi.org/ 10.1002/qj.828.

Del Genio, A. D., 2012: Representing the sensitivity of convective cloud systems to tropospheric humidity in general circulation models. Surv. Geophys., 33, 637-656, https://doi.org/10.1007/ s10712-011-9148-9.

Derbyshire, S. H., I. Beau, P. Bechtold, J.-Y. Grandpeix, J.-M. Piriou, J.-L. Redelsperger, and P. M. M. Soares, 2004: Sensitivity of moist convection to environmental humidity. Quart. J. Roy. Meteor. Soc., 130, 3055-3079, https://doi.org/10.1256/qj.03.130. 
Gent, P. R., and Coauthors, 2011: The Community Climate Model version 4. J. Climate, 24, 4973-4991, https://doi.org/10.1175/ 2011JCLI4083.1.

Hanf, F. S., H. Annamalai, A. Rinke, and K. Dethloff, 2017: South Asian summer monsoon breaks: Process-based diagnostics in HIRHAM5. J. Geophys. Res. Atmos., 122, 4880-4902, https:// doi.org/10.1002/2016JD025967.

Hannah, W. M., and E. D. Maloney, 2011: The role of moistureconvection feedbacks in simulating the Madden-Julian oscillation. J. Climate, 24, 2754-2770, https://doi.org/10.1175/2011JCLI3803.1.

— and - 2014: The moist static energy budget in NCAR CAM5 hindcasts during DYNAMO. J. Adv. Model. Earth Syst., 6, 420-440, https://doi.org/10.1002/2013MS000272.

Hirons, L., P. Inness, F. Vitart, and P. Bechtold, 2013a: Understanding advances in the simulation of intraseasonal variability in the ECMWF model. Part I: The representation of the MJO. Quart. J. Roy. Meteor. Soc., 139, 1417-1426, https://doi.org/10.1002/qi.2060.

$\ldots, \ldots, \ldots$, and $-\ldots 13 \mathrm{~b}$ : Understanding advances in the simulation of intraseasonal variability in the ECMWF model. Part II: The application of process-based diagnostics. Quart. J. Roy. Meteor. Soc., 139, 1427-1444, https://doi.org/10.1002/qj.2059.

Hirota, N., Y. N. Takayabu, M. Watanabe, M. Kimoto, and M. Chikira, 2014: Role of convective entrainment in spatial distributions of and temporal variations in precipitation over tropical oceans. J. Climate, 27, 8707-8723, https://doi.org/ 10.1175/JCLI-D-13-00701.1.

Holloway, C. E., and J. D. Neelin, 2009: Moisture vertical structure, column water vapor, and tropical deep convection. J. Atmos. Sci., 66, 1665-1683, https://doi.org/10.1175/2008JAS2806.1.

Houze, R. A., 1997: Stratiform precipitation in regions of convection: A meteorological paradox? Bull. Amer. Meteor. Soc., 78, 2179-2196, https://doi.org/10.1175/1520-0477(1997)078<2179: SPIROC $>2.0 . \mathrm{CO} ; 2$.

Huffman, G. J., and Coauthors, 2007: The TRMM Multisatellite Precipitation Analysis (TMPA): Quasi-global, multiyear, combinedsensor precipitation estimates at fine scales. J. Hydrometeor., 8, 38 55, https://doi.org/10.1175/JHM560.1.

_ , R. F. Adler, D. T. Bolvin, and G. Gu, 2009: Improving the global precipitation record: GPCP version 2.1. Geophys. Res. Lett., 36, L17808, https://doi.org/10.1029/2009GL040000.

,,$---\longrightarrow$, and E. J. Nelkin, 2010: The TRMM Multisatellite Precipitation Analysis (TMPA). Satellite Rainfall Applications for Surface Hydrology, F. Hossain and M. Gebremichael, Eds., Springer Verlag, 3-22.

Klingaman, N. P., and S. J. Woolnough, 2014a: The role of air-sea coupling in the simulation of the Madden-Julian oscillation in the Hadley Centre model. Quart. J. Roy. Meteor. Soc., 140, 2272-2286, https://doi.org/10.1002/qj.2295.

— , and — 2014b: Using a case-study approach to improve the Madden-Julian oscillation in the Hadley Centre model. Quart. J. Roy. Meteor. Soc., 140, 2491-2505, https://doi.org/10.1002/qj.2314.

Levine, R. C., A. G. Turner, D. Marathayil, and G. M. Martin, 2013: The role of northern Arabian Sea surface temperature biases in CMIP5 model simulations and future projections of Indian summer monsoon rainfall. Climate Dyn., 41, 155-172, https://doi.org/10.1007/s00382-012-1656-x.

Lin, Y., and M. Zhao, 2013: Precipitation partitioning, tropical clouds, and intraseasonal variability in GFDL AM2. J. Climate, 26, 5453-5466, https://doi.org/10.1175/JCLI-D-12-00442.1.

Ma, H. Y., and Coauthors, 2014: On the correspondence between mean forecast errors and climate errors in CMIP5 models. J. Climate, 27, 1781-1798, https://doi.org/10.1175/JCLI-D-1300474.1.
Maloney, E. D., 2009: The moist static energy budget of a composite tropical intraseasonal oscillation in a climate model. J. Climate, 22, 711-729, https://doi.org/10.1175/2008JCLI2542.1.

Marathayil, D., A. G. Turner, L. C. Shaffrey, and R. C. Levine, 2013: Systematic winter sea-surface temperature biases in the northern Arabian Sea in HiGEM and the CMIP3 models. Environ. Res. Lett., 8, 014028, https://doi.org/10.1088/1748-9326/8/1/014028.

Martin, G. M., S. F. Milton, C. A. Senior, M. E. Brooks, S. Ineson, T. Reichler, and J. Kim, 2010: Analysis and reduction of systematic errors though a seamless approach to modeling weather and climate. J. Climate, 23, 5933-5957, https://doi.org/ 10.1175/2010JCLI3541.1.

McCreary, J. P., P. K. Kundu, and R. L. Molinari, 1993: A numerical investigation of dynamics, thermodynamics and mixed-layer processes in the Indian Ocean. Prog. Oceanogr., 31, 181-244, https://doi.org/10.1016/0079-6611(93)90002-U.

Neale, R. B., J. H. Richter, and M. Jochum, 2008: The impact of convection on ENSO: From a delayed oscillator to a series of events. J. Climate, 21, 5904-5924, https://doi.org/10.1175/ 2008JCLI2244.1.

- and Coauthors, 2010: Description of the NCAR Community Atmosphere Model (CAM 4.0). NCAR Tech. Note NCAR/ TN-485+STR, 212 pp., www.cesm.ucar.edu/models/ccsm4.0/ cam/docs/description/cam4_desc.pdf.

- and Coauthors, 2012: Description of the NCAR Community Atmosphere Model (CAM 5.0). NCAR Tech. Note NCAR/ TN-486+STR, 274 pp., www.cesm.ucar.edu/models/cesm1.0/ cam/docs/description/cam5_desc.pdf.

Neelin, J. D., and I. M. Held, 1987: Modeling tropical convergence based on the moist static energy budget. Mon. Wea. Rev., 115, 3-12, https:// doi.org/10.1175/1520-0493(1987)115<0003:MTCBOT>2.0.CO;2. , and H. Su, 2005: Moist teleconnection mechanisms for the tropical South American and Atlantic sector. J. Climate, 18, 3928-3950, https://doi.org/10.1175/JCLI3517.1.

Oueslati, B., and G. Bellon, 2013: Convective entrainment and large-scale organization of tropical precipitation: Sensitivity of the CNRM-CM5 hierarchy of models. J. Climate, 26, 29312946, https://doi.org/10.1175/JCLI-D-12-00314.1.

Raymond, D. J., S. L. Sessions, A. H. Sobel, and Ž. Fuchs, 2009: The mechanics of gross moist stability. J. Adv. Model. Earth Syst., 1 (3), https://doi.org/10.3894/JAMES.2009.1.9.

, Ž. Fuchs, S. Gjorgjievska, and S. Sessions, 2015: Balanced dynamics and convection in the tropical troposphere. J. $A d v$. Model. Earth Syst., 7, 1093-1116, https://doi.org/10.1002/ 2015MS000467.

Rodwell, M. J., and B. J. Hoskins, 1995: A model of the Asian summer monsoon. Part 2: Cross-equatorial flow and PV behavior. J. Atmos. Sci., 52, 1341-1356, https://doi.org/10.1175/ 1520-0469(1995)052<1341:AMOTAS > 2.0.CO;2.

, and $-1996:$ Monsoons and the dynamics of deserts. Quart. J. Roy. Meteor. Soc., 122, 1385-1404, https://doi.org/ 10.1002/qj.49712253408.

Shenoi, S. S. C., D. Shankar, and S. R. Shetye, 2002: Differences in heat budgets of the near-surface Arabian Sea and Bay of Bengal: Implications for the summer monsoon. J. Geophys. Res., 107, 3052, https://doi.org/10.1029/2000JC000679.

Sperber, K. R., H. Annamalai, I. S. Kang, A. Kitoh, A. Moise, A. Turner, B. Wang, and T. Zhou, 2013: The Asian summer monsoon: An intercomparison of CMIP5 vs. CMIP3 simulations of the late 20th century. Climate Dyn., 41, 2711-2744, https://doi.org/10.1007/s00382-012-1607-6.

Stephens, G. L., S. van den Heever, and L. Pakula, 2008: Radiative-convective feedbacks in idealized states of 
radiative-convective equilibrium. J. Atmos. Sci., 65, 38993916, https://doi.org/10.1175/2008JAS2524.1.

Su, H., and J. D. Neelin, 2002: Teleconnection mechanisms for tropical descent anomalies during El Niño. J. Atmos. Sci., 59, 2694-2712, https://doi.org/10.1175/1520-0469(2002)059<2694: TMFTPD $>2.0 . \mathrm{CO} ; 2$.

Taylor, K. E., R. J. Stouffer, and G. A. Meehl, 2012: An overview of CMIP5 and the experiment design. Bull. Amer. Meteor. Soc., 93, 485-498, https://doi.org/10.1175/BAMS-D-11-00094.1.

Tompkins, A. M., 2001: Organization of tropical convection in low vertical wind shears: The role of water vapor. J. Atmos. Sci., 58, 529-545, https://doi.org/10.1175/1520-0469(2001)058<0529: OOTCIL $>2.0 . \mathrm{CO} ; 2$.

Tulich, S. N., and B. E. Mapes, 2010: Transient environmental sensitivities of explicitely simulated tropical convection. J. Atmos. Sci., 67, 923-940, https://doi.org/10.1175/2009JAS3277.1.

Wang, X., and M. Zhang, 2013: An analysis of parameterization interactions and sensitivity of single-column model simulations to convection schemes in CAM4 and CAM5. J. Geophys. Res., 118, 8869-8880, https://doi.org/10.1002/JGRD.50690.
Webster, P. J., V. O. Magaña, T. N. Palmer, J. Shukla, R. A. Tomas, M. Yanai, and T. Yasunari, 1998: Monsoons: Processes, predictability, and the prospects for prediction. J. Geophys. Res., 103, 14 451-14 510, https://doi.org/10.1029/97JC02719.

Zhang, G. J., 2009: Effects of entrainment on convective available potential energy and closure assumptions in convection parameterization. J. Geophys. Res. Atmos., 114, D07109, https:// doi.org/10.1029/2008JD010976.

_ , and N. A. McFarlane, 1995: Sensitivity of climate simulations to the parameterization of cumulus convection in the Canadian Climate Centre general circulation model. Atmos.-Ocean, $\mathbf{3 3}$ 407-446, https://doi.org/10.1080/07055900.1995.9649539.

Zhao, M., and Coauthors, 2018a: The GFDL global atmospheric and land model AM4.0/LM4.0: 1. Simulations characteristics with prescribed SSTs. J. Adv. Model. Earth Syst., 10, 691-734, https://doi.org/10.1002/2017MS001208. , and Coauthors, 2018b: The GFDL global atmospheric and land model AM4.0/LM4.0: 2. Model description, sensitivity studies, and tuning strategies. J. Adv. Model. Earth Syst., 10, 735-769, https://doi.org/10.1002/2017MS001209. 